\title{
BIM-Based End-of-Lifecycle Decision Making and Digital Deconstruction: Literature Review
}

\author{
Arghavan Akbarieh ${ }^{1}\left(\mathbb{D}\right.$, Laddu Bhagya Jayasinghe ${ }^{2}{ }^{\oplus}$, Danièle Waldmann ${ }^{2}(\mathbb{D}$ and \\ Felix Norman Teferle ${ }^{1, *(1)}$ \\ 1 Faculty of Science, Technology and Medicine, Campus Kirchberg, University of Luxembourg, \\ 1359 Luxembourg, Luxembourg; arghavan.akbarieh@uni.lu \\ 2 Faculty of Science, Technology and Medicine, Campus Belval, University of Luxembourg, \\ 4365 Esch-sur-Alzette, Luxembourg; bhagya.jayasinghe@uni.lu (L.B.J.); daniele.waldmann@uni.lu (D.W.) \\ * Correspondence: norman.teferle@uni.lu
}

Received: 29 January 2020; Accepted: 23 March 2020; Published: 28 March 2020

\begin{abstract}
This article is the second part of a two-part study, which explored the extent to which Building Information Modelling (BIM) is used for End-of-Lifecycle (EoL) scenario selection to minimise the Construction and Demolition Waste (CDW). The conventional literature review presented here is based on the conceptual landscape that was obtained from the bibliometric and scientometric analysis in the first part of the study. Seven main academic research directions concerning the BIM-based EoL domain were found, including social and cultural factors, BIM-based Design for Deconstruction (DfD), BIM-based deconstruction, BIM-based EoL within LCA, BIM-aided waste management, Material and Component Banks (M/C Banks), off-site construction, interoperability and Industry Foundation Classes (IFC). The analysis highlights research gaps in the path of raw materials to reusable materials, i.e., from the deconstruction to $\mathrm{M} / \mathrm{C}$ banks to DfD-based designs and then again to deconstruction. BIM-based EoL is suffering from a lack of a global framework. The existing solutions are based on local waste management policies and case-specific sustainability criteria selection. Another drawback of these ad hoc but well-developed BIM-based EoL prototypes is their use of specific proprietary BIM tools to support their framework. This disconnection between BIM tools and EoL tools is reportedly hindering the BIM-based EoL, while no IFC classes support the EoL phase information exchange.
\end{abstract}

Keywords: Building Information Modelling; deconstruction; design for deconstruction; reusable materials; interoperability; life cycle assessment; offsite construction; Construction and Demolition Waste; digital twin; Building Stock 4.0

\section{Introduction}

Unsustainable resource consumption and climate change repercussions have contributed to a $60 \%$ degradation in Earth's ecosystem services over the last half century [1]. Housing and mobility, as well as nutrition needs, are reportedly responsible for about $70 \%-80 \%$ of all environmental impacts in the industrialised countries [1]. Thus, structures and infrastructure correlate with the negative environmental impacts associated with the Anthropocene epoch. In the European Union (EU), the construction industry accounts for $50 \%$ of raw material consumption, $42 \%$ of final energy use and $35 \%$ greenhouse gas emissions to generate $10 \%$ of the Gross Domestic Product (GDP) per year [1,2]. Hence, in comparison to other industrial sectors, the construction sector is a voracious resource and energy consumer and carbon producer. Using such a massive amount of input leads to a considerable amount of waste output in terms of Construction and Demolition Waste (CDW). CDW is generated in different stages of a building's lifecycle and forms up to 30\% of the EU's waste stream [3-5]. Waste can be generated in the construction phase due to design errors, on-site mistakes, workflow confusions, 
unpredicted plant malfunctions, renovation [6-9], or during the End-of-Lifecycle (EoL) phase when the building's service life is over.

Waste typologies vary from country to country. In Korea, wastes are separated into combustible, incombustible and mixed [10], while in the United Kingdom, wastes are categorised as light mixed, compatible waste, mixed construction waste, mixed inert waste and so on [11]. Different types of wastes that originate from different types of construction materials have different environmental impacts due to the variability of materials during the lifecycle [11,12]. Waste source detection is the key to identifying waste outputs. Therefore, it is crucial to identify the potential waste types from the combination of materials used in the design phase. Lockrey et al. [13] believed that an essential step in waste segmentation is a material classification, which is an important knowledge limitation in the current environmental assessment methodologies. Furthermore, CDW does not only come from residential or office projects, but also large-scale projects, such as nuclear or thermal power plants, which can produce a considerable amount of waste, according to Seethapathy et al. [6].

The amounts and types of waste are dependent on the chosen EoL scenario for a building. Three EoL scenarios can be anticipated, namely demolition, selective demolition, or deconstruction. Demolition is conventionally practised by completely demolishing a structure without any discrimination between the materials and components in the buildings. The output of this scenario (i.e., CDW) is usually sent to landfills. According to the European Waste Directive 2008/98/EC [14], disposal of materials is the least sustainable action in the waste management hierarchy and should be avoided as much as possible. Consequently, the selective demolition approach encourages the separation and sorting of materials to salvage those that could be used in other projects or could be recycled. If CDW is managed well, it can be used as secondary raw material [15]. Nevertheless, since a portion of the reusable or recyclable elements is diverted from landfills, selective demolition is more environmentally friendly than demolition [16].

The other alternative EoL solution is deconstruction. Through deconstruction, materials and components with reusability capability are disassembled and are further used in another project. Therefore, valuable materials and components will remain in the market value chain for a more extended period of time in order to fulfil their expected service life. In many cases, the expected lifetime of a component is longer than that of the host building. Hence, keeping the components in the market would make up for the initial costs and contributes to a sustainable built environment. It is paramount to keep in mind that some elements are suited for deconstruction but not for reuse, since they do not pass the reusability assessment tests [8,17]. According to Waldmann [18], the use of reusable materials and deconstructed components in the design phase is gaining momentum in the Architecture, Engineering, Construction, Owner and Operator (AECOO) industry. Thus, continuing the business-as-usual practice of using newly sourced materials is no longer a desirable option.

Reducing the waste outputs of the AECOO sector leads to a decrease in resource extraction and land-use footprint [19]. This assists the restoration of the natural capital and ecological resources of the planet Earth. As a result, materials and lands are saved from being wasted and energy and carbon emissions would be controlled, since the re-utilisation of the elements would spread their negative environmental externalities over more than one lifecycle $[18,20]$. Deconstruction can enable the diversion of materials (that have enough capacity to be reused without endangering the health and safety of human beings) from landfills and their reintroduction into the market, which signifies a combination of environmental sustainability and Circular Economy (CE) approaches. $\mathrm{CE}$ advocates for a zero-waste supply chain and closed-loop material cycle in order to achieve a carbon-neutral, resource-efficient and competitive economy [21,22]. A closed-loop material cycle means extraction-production-use-reuse-recycling (as much as possible). This is in opposition to the linear economy's extraction-production-use-disposal schema. Figure 1 compares these two business models in the context of the building industry [23,24]. CE values the individual lifecycle of materials and components that constructs the final product and promotes Sustainable Materials Management (SSM) $[1,25]$. Considering the future use scenarios of building elements has resulted in a variety of new 
building design strategies, such as reversible building design and design for deconstruction, also known as design for disassembly (DfD) [24]. These have all given popularity to the term "circular building", which is a climate-proof, resilient and sustainable building with considerations for its EoL phase to close the material loop.

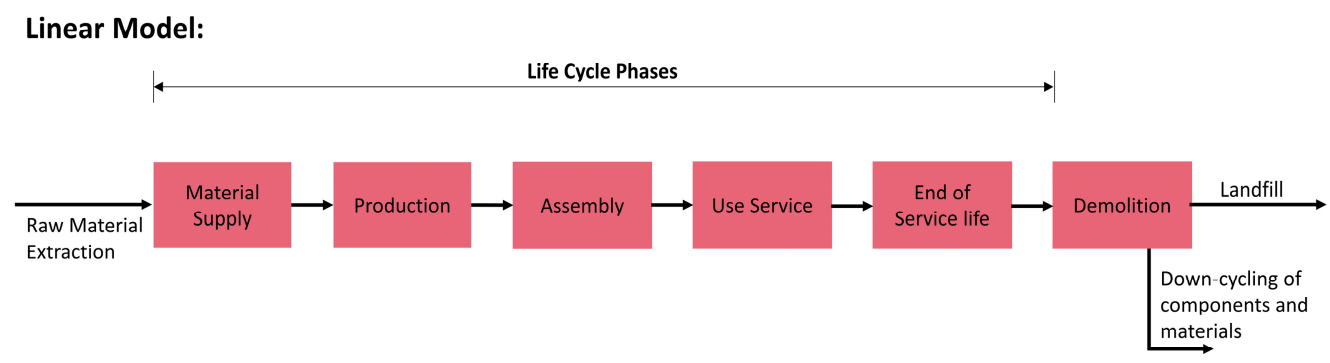

Cyclic Model:

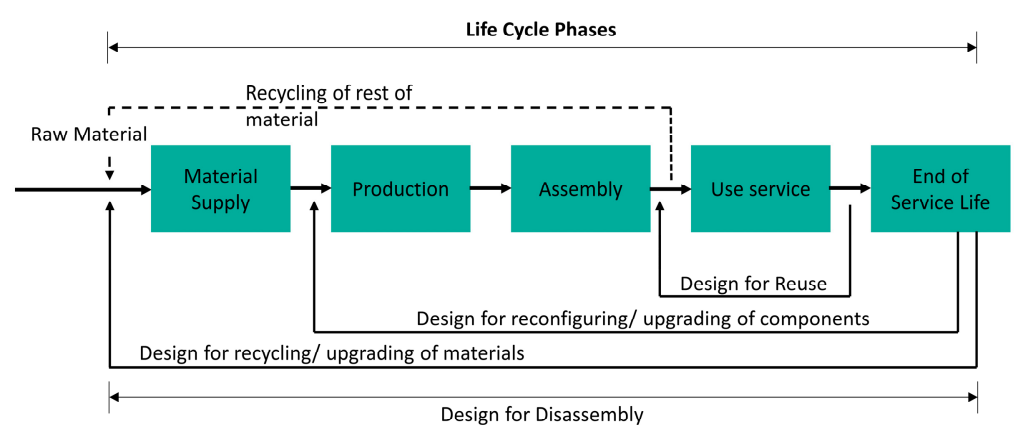

Figure 1. A comparison between the linear (top) and circular (bottom) business models in the construction industry. The linear model focusses on design for one EoL, while the circular model allows the reuse of materials for multiple designs. The image has been modified from [24].

The execution of a sustainable and circular EoL scenario requires reliable and error-free data. Such data requirements can be met by using digital models of buildings. In fact, with the digital revolution that is proliferating in every sector, the AECOO's trajectory is also set toward the Building Stock 4.0, which is a digitalised building stock. Building Stock 4.0 is realised through the digital construction ecosystem, in which digital twins represent the real-world buildings. The digital twins or Building Information Models (BIMs) are created through the Building Information Modelling (also known as BIM) methodology. With this methodology, we can create a digital 3D model of a building in which both geometric information and non-geometric properties of all the elements are included [26]. BIM is an intelligent and object-oriented model. As a result, any modification of an object (in terms of quantity and quality) would be automatically reflected in all of the views, sections and schedules of the model. Having a BIM helps with automatically obtaining the overall volume of materials, the material properties and the dimensions of the objects. Coming back to EoL scenarios, it is possible to add a layer of information to each object in BIM in order to prepare them for the future EoL applications, such as deconstruction guidelines, guarantees, environmental assessment scores and legal requirements. Thus, BIM facilitates deconstruction planning and execution and enables a culture for digital deconstruction as a part of a sustainable and circular Building Stock 4.0. The focus of this study is BIM-based EoL, leveraging BIM for EoL decision-making and waste estimation of different design alternatives. Some experts called the BIM-based EoL the 8D BIM [27], although there are still discussions within academia about whether BIM-based decommissioning is another dimension of BIM or not [28]. Other dimensions of BIM are visualised in Figure 2.

Using BIM has few competitive advantages for demolition activities, since the whole building is demolished and there is no need for locating the materials within the building in advance. For deconstruction activities, however, having a digital twin helps with monitoring the overall 
status and health of the components as well as their foreseen deconstruction guidelines. In fact, the use of BIM for an effective pre-deconstruction audit is suggested in the principles for circular design of buildings by the European Commission in order to assess the recovery, reuse and recycling potential of material streams [29]. Moreover, deconstruction is an activity that is to happen in, for instance, 50 years from the time that the building is designed and constructed. There is a strong probability that parties who had not participated in the construction phase are going to deconstruct the building, e.g., owners or new contractors. These parties need to locate different elements, estimate the reusable or CDW quantities, check the assessment scores and perform necessary measures before deconstruction, all of which can be easily satisfied by BIM in a virtual digital environment.

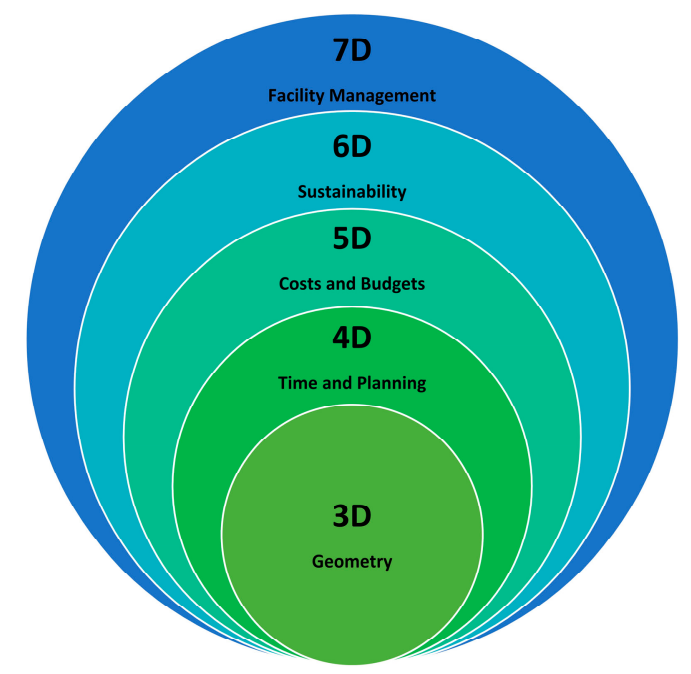

Figure 2. Dimensions of Building Information Modelling (BIM).

This research aims to provide a holistic overview of the BIM-based EoL concepts through a mixed-methodology literature review. In this paper, a conventional literature review is presented. Although previous studies have reviewed different aspects of BIM and CDW, the point of novelty of this research is the specific focus on the application of BIM for the EoL phase of buildings. However, our literature collection is limited to articles that were retrieved for metadata analysis through the scientometric and bibliometric methodologies that constitute the first part of the study [30]. However, some relevant publications were added to our collection to provide a better overview of the topics. This article is structured in five sections, starting with a brief introduction in Section 1 . The methodology and data retrieval procedures are explained in Section 2. Subsequently, the results of the literature review are delivered in Section 3, which is followed by Section 4, Discussions. Eventually, concluding remarks are presented in Section 5.

\section{Materials and Methods}

Through a systematic mixed-review methodology, a state-of-the-art review of BIM-based EoL and associated topics is presented. Prior to the conventional literature review that is delivered in Section 3, the big picture of the BIM-based EoL research domain was delineated through bibliometric and scientometric analysis, for which the results are separately published in [30]. The bibliometric and scientometric analysis does not analyse the main content (i.e., body text of an article), but only the metadata (e.g., authors, affiliations, keywords, references, titles and so forth). The bibliometric and scientometric analyses are popular methods for "science mapping" in order to investigate the social networks between scientific groups as well as their scientific outputs to find useful insights into the cognitive structure of a research domain. Through science mapping networks, popular research themes, chronological research trends, conceptual relationships between keywords and the big picture of a research domain are visualised [31-33]. In this study, the bibliometric and scientometric 
analyses were performed by using the Bibliometrix package v.2.1.1 [31] in RStudio v.3.5.1 [34]. In short, the articles and their associated metadata were extracted from the Web of Science (WoS) and Scopus for English-language journal articles published from 2009 to February 2019. If a scientific peer-reviewed article did not meet the search rule criteria (i.e., keywords, language, type, time), they were not included in our analysis. Figure A1 in Appendix A demonstrates the keywords and the overall metadata retrieval procedure. Based on the results of this analysis (especially the conceptual structure map, as shown in Figure A2 in Appendix A), an in-depth literature review was conducted.

Once the bibliometric and scientometric analysis was performed, the conceptual maps were created (Figure A2 in Appendix A) and the top $20 \%$ of the contributing publications were plotted in the associated factorial maps (Figure A3 in Appendix A). For interested readers, more explanations about the aforementioned maps as well as the bibliometric and scientometric analysis are presented in Appendix A. The top $20 \%$ of contributing articles based on factorial maps composed the first group of reviewed articles in the study. This process was inspired by the work of Wang et al. [35], who used the "80/20 rule", which is also known as "Pareto distribution" [36]. To explain the 80/20 rule in the context of our methodology, one can consider that $20 \%$ of the all of the documents in the article collection are most probably responsible for providing the $80 \%$ of the essential (and most relevant) content. In contrast, the remaining $80 \%$ of the papers contribute to about $20 \%$ of the concepts related to BIM-based EoL. This methodology proved to be useful, as the influential articles that offer new BIM-based EoL or CDW management research outputs were indeed in the top $20 \%$ of the data pool shown in Figure A1.

During this process, 88 peer-reviewed articles were screened for review. After reading the articles, irrelevant papers were omitted. To support the definitions and arguments that were discussed in the articles, we added a handful of relevant resources, including books, EU guidelines and conference articles, to this BIM-based EoL critical literature review. An overview of our systematic mixed-review methodology is presented in Figure 3.

Part 1

Bibliometric and scientometric Analysis

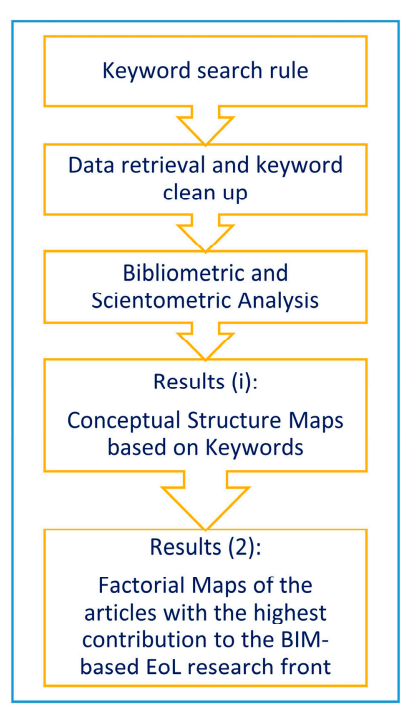

Part 2

Critical Literature Review

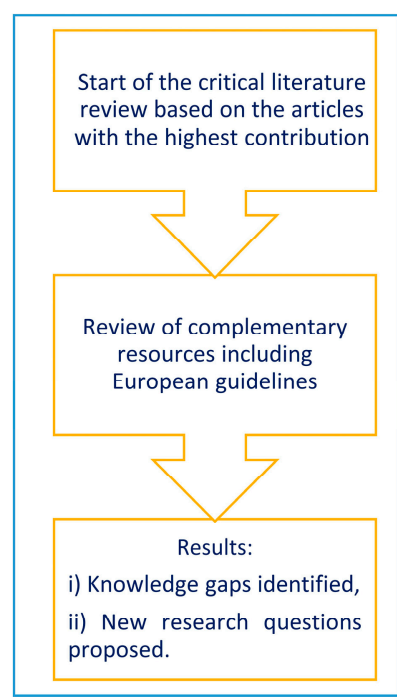

Figure 3. The systematic mixed-review methodology for BIM-based End-of-Lifecycle (EoL) scenarios. Scientometric and bibliometric methodologies were used in Part 1 [30], which set the basis for the conventional literature review in Part 2.

\section{Results}

After the critical review of the publications, the main points are categorised and are presented in the following sub-sections. 


\subsection{Social and Cultural Barriers in Deconstruction and DfD Practices}

Regardless of the waste generation due to the construction/deconstruction techniques and designs, human factors and cultural attitudes can also lead to waste production. Ajayi et al. [7] found that a waste inevitability mindset, blameshift and an attitude of evading responsibility in the construction industry are responsible for waste generation. Thus, clear lines of responsibility are necessary for better CDW management [13].

Even though waste can be reduced in the optimised design and decommissioning phases, the fact that the client pays for the wasted or landfilled materials makes the whole concept of less waste generation less attractive for on-site practitioners [7]. Similarly, decision-makers usually prioritise project delivery time over waste prevention, which means that cost-saving is more important than the environment.

Furthermore, there is a direct link between waste production and the engineering and management planning in the early design stages [6]. Rose and Stegemann [8] discovered that recycling is the primary EoL solution for many projects. Although in their study, some contractors stated their willingness to consider the possibility of deconstruction and reuse of the components, not all did. However, Rose and Stegemann [8] argued that deconstruction decision-making is further hindered because of the uncertainties that exist in the minds of contractors and on-site engineers, as they do not know where these deconstructed components are going to be (re)used in the future. This lack of information stops the contractors from making decisions about the disassembly of the components while they are working on-site. The spread of the deconstruction practices might encourage demolition contractors to shift to deconstruction practices and take into account the future of individual elements [37].

The dormant market of deconstructed but re-usable construction products could be another reason for the weak participation of construction participants. However, Sanchez and Hass [38] stated that construction material costs are lower in a reuse building project in comparison to a business-as-usual project. They further emphasised the social benefits of having a reusable resource market, in which skilled labour expenses, as well as employment, are higher in projects where reusable elements are utilised.

Moreover, in practice, many construction activities begin with incomplete designs and contract documentation or incorrect information, which eventually lead to waste due to rework [7]. This type of waste is referred to as "make-do waste". A collaborative BIM ecosystem can prevent the waste of time, costs and resources that come from the make-do culture. This is because BIM helps with clear visualisation, early error detection and virtual constructability controls before the actual construction [39]. Another reported issue besides the discrepancies between drawings is illogical designs that again lead to rework and construction waste [40].

Ajayi et al. [41] argued that full adoption of BIM in the construction industry is possible once waste management solutions are BIM compliant and integrated with the project delivery methods. Project delivery methods are important considerations because the workflows of different methodologies require different approaches to BIM methodology. It seems that traditional project delivery methods are less in tune with BIM than conventional construction methods. For instance, Design-Bid-Built, Conventional Site-case and Renovation methodologies have the lowest compatibility with BIM in comparison to the Prefabrication and Design-Build project delivery methods [42]. Correspondingly, construction techniques are other influential factors for environmental impacts of the building and the generated wastes-this is a critical point to be considered in BIM-based waste management tools [43].

BIM as a methodology and set of processes helps to create digital twins of the real-world buildings [26]. Some of the previously manual calculations and estimations that should have been derived from paper-based designs or Computer Aided Design (CAD)-based designs are now automatically prepared through BIM. Such task automation offers time, money and man-hour savings while it reduces human-made errors. As a result, environmental impact calculation tools aspire to use the automation and speed that BIM offers to their advantage [43]. 
The automation of processes also brings enhanced communications. Li et al. [44] stated that existing communication barriers in the AECOO industry are the outcome of traditional design practices as well as the fragmented nature of this industry, which can be improved through BIM. A higher level of automation and communication opens the door to better collaboration. Lack of cooperation and collaboration is reported as a reason for ineffective CDW management in Vietnam [13]. The degree of collaboration in a process increases with the level of maturity of the application of information technology [26]. Four levels of maturity are defined for BIM, i.e., "BIM Levels", as illustrated in Figure 4. In the lowest level, Level 0 BIM, the traditional drawings, which are either produced by CAD or by hand, are circulated between partners. In the next level, Level 1 BIM, working with a mixture of 2D drawings for drafting and 3D CAD models for conceptual design is the common practice. Subsequently, Level 2 BIM refers to collaborative work where stakeholders have their individual 3D models. In this level, the information is exchanged through a standard file format, e.g., Industry Foundation Classes (IFC, ISO 16739-1:2018 [45]) or Construction Operations Building Information Exchange (COBie, BS 1192-4:2014 [46]), to create a federated model. However, full collaboration in one centralised model shared between all stakeholders signifies the highest level of maturity in BIM, which is Level 3 [26]. Level 3 has the potential to manage the complete lifecycle information in an integrated workflow and open information exchange between project participants. Information can be reused through one model [43], since BIM is inherently a collaborative platform. Hence, many construction participants perceive BIM as a remedy for the inadequate communication and collaboration that is prevalent in the AECOO $[7,47,48]$. The combination of the IT-enhanced communication and collaboration practices and object-oriented design tools lead to the BIM-based coordinated design. In a similar vein, the coordination capability of BIM would improve deconstruction planning and execution [49], while it can also assist engineers in providing digital deconstruction guidelines. Additionally, the automation and accessibility of information reduce the guesswork of contractors during the deconstruction phase.

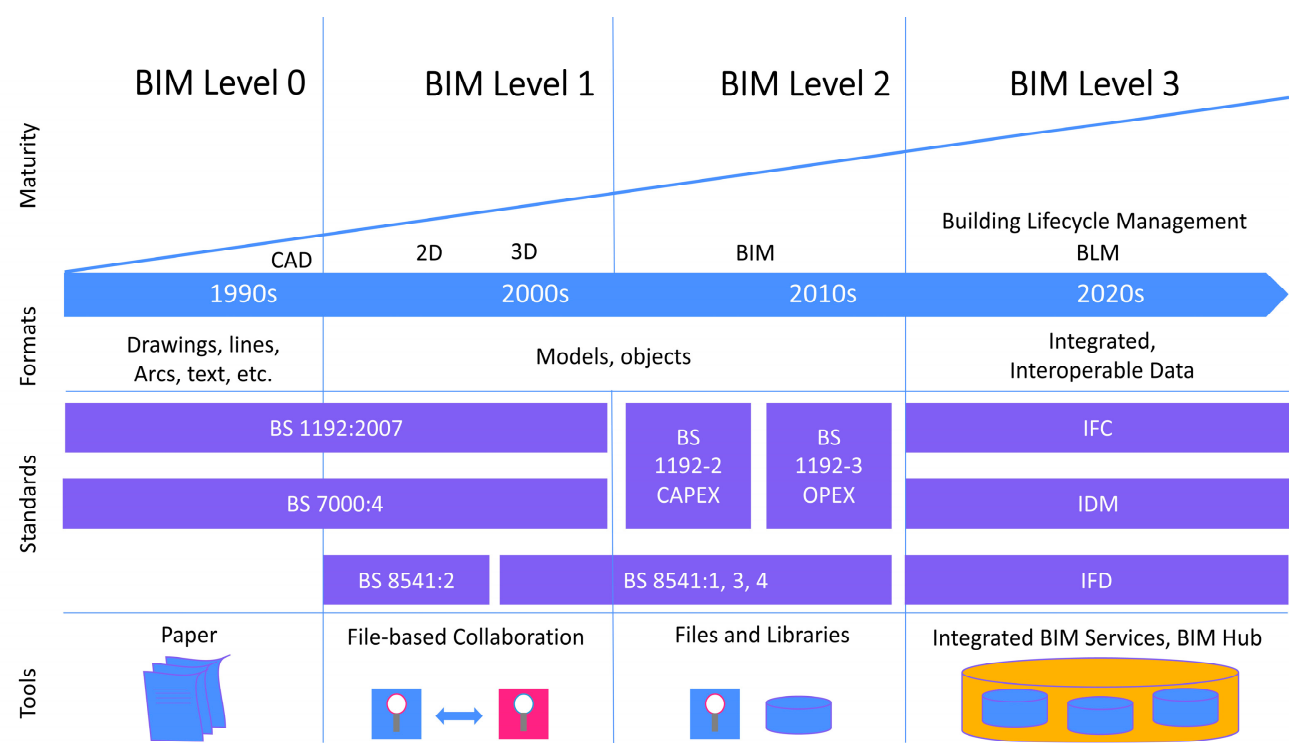

Figure 4. The BIM maturity model, including PAS 1192-2:2013 [50] and BSI 1192-4:2014 [46] standards, modified from [26].

Other issues to consider in BIM-based EoL social challenges are regulations and legislation, especially in higher education. Human capital seems to be low when it comes to BIM-based deconstruction and DfD. Densley Tingley et al. [37] believed that architects and engineers should be trained as skillful designers with reused elements in order to deepen the diffusion of reusable design in the industry. Moreover, BIM education must be integrated into university curriculums in order to bridge the actual needs of the industry and the skills of new graduates [51,52]. A socio-technical 
issue regarding BIM adoption in every organisational level is the high cost of BIM tool licenses and training [26,53-55]. If educated graduates have the necessary BIM-based DfD skills, the firms have to invest less in training their recruits with BIM and DfD concepts. This can potentially reduce the fear throughout the AECOO industry that the technological superiority and initial capital of big companies would outrun smaller firms with lower budgets. Therefore, regulation can enhance the adaptation of BIM-based DfD within the industry, as well as bolstering the strategic guidelines, actions and tools [56,57].

Chong et al. [58] found a severe lack of standards and guidelines for Renovation and Deconstruction (R\&D) as well as a need for using BIM in various aspects of refurbishment and demolition. Renovation scenarios, unlike new construction scenarios, have no universally acceptable norms or business processes [59]. What Chong et al. [58] considered as R\&D consists of the reuse of recycled materials in buildings as well as providing accurate information about the materials through BIM. They also insisted that BIM standards must incorporate R\&D thinking, while BIM should comply with standard sustainability assessments [58]. Additionally, they believed that innovative procurement could benefit from BIM, although this topic is not fully explored by researchers.

Finally, BIM can facilitate the green building certification process, in which points are awarded to the degree of reusability or recyclability of the materials and components, as well as CDW minimisation [60,61]. Green building certificates can be linked with waste management prototypes to receive some waste indices automatically [37]. However, no such working prototype exists at the moment.

\subsection{BIM-Based DfD and BIM-Based Deconstruction Solutions and Challenges}

Design for deconstruction is not an entirely new concept. Its modern definition is polished with the sustainability and circularity ideologies - that is, to design a sustainable building with elements that can be reintroduced to the market for future reuse. Adding the digitalisation layer (in the form of BIM) to this definition enhances its complexity. Therefore, BIM-based DfD is a mixture of immature or underdeveloped topics with few practical examples in the modern history of construction. A significant hindrance in the widespread application of BIM-based DfD is perceived to be the disconnection between BIM and EoL/DfD management and planning tools [41]. The construction industry seems eager to use BIM and DfD tools more and more in tandem for achieving better lifecycle management and data transparency. While the collaborative environment of BIM is attractive for those interested in BIM-based construction, it seems that the capacity of BIM tools to store a huge chunk of information is more attractive for those involved in DfD. One reason is the enormous amount of DfD documentation and the unknown time of the actual deconstruction activities in the future when the deconstruction documents must be available [62].

To find the most sustainable deconstruction solution in terms of embodied carbon and energy, Akbarnezhad et al. [62] designed a BIM-based study with four different EoL scenarios: (A) Conventional demolition and landfilling, (B) conventional demolition and landfilling but recycling concrete and steel, (C) disassembly of DfD-oriented components at the end of the first lifecycle, while everything is entirely demolished at the end of the second lifecycle, and (D) disassembly of DfD-oriented components at the end of the first lifecycle, while concrete and steel are recycled at the end of the second lifecycle. They took into account factors including the embodied energy of materials and components, transportation considerations, costs and market prices. Based on their results, the fourth solution is the most socially and economically sustainable option. Their results comply with the results of another study by Densley Tingley and Davison [20], in which they demonstrated that when an element (such as a steel beam) with an individual life span greater than that of its embedded building is used in more than one life, the produced carbon emissions are divided by the lives and are hence much lower. Various building components have different life expectancies [63] that can be stored and later queried per demand in BIM. On that note, building usage that is directly related to occupancy, activity and behaviour dramatically affects the lifetime of the building components [63]. Furthermore, Densley Tingley and 
Davison [20] showed that a DfD-based building produces lower carbon emissions either throughout the whole lifecycle or only in the decommissioning phase.

Nevertheless, DfD would be only successful if the components are effectively retrieved after the lifecycle of the designated building is finished. Any building can be built, but to deconstruct it successfully (after many years of occupancy when the initial designers and contractors are nowhere to be found) is a hard task. Hence, in a novel approach, Akinade et al. [64] targeted the technical and non-technical critical success factors that are necessary for effective material recovery through DfD. They found that stringent legislation and policies, design process and competency for deconstruction, design for material recovery, design for material reuse and design for building flexibility are the generally acceptable success factors for approaching the EoL disposal of buildings in a sustainable way. BIM can help with the estimation of the EoL properties of materials while improving the disassembly process and sequence stimulation [64].

Materials, regulations, construction methods, societal needs and tastes will change over time, which might lead to the abolition of deconstructable buildings and reusable components [8]. Therefore, any proposed BIM-based framework must take the time-dependable factors described above into account. If all of the information is recorded in a BIM, then reusable components can be easily adjusted to the unforeseen changes in the future. An intelligent object-based model (i.e., BIM) can be modified more easily than CAD plans. In this way, it will also be easier for future buildings to explore the possibilities of EoL with the technologies of their own time.

Many researchers have introduced innovative solutions to proliferating the systematic usage of BIM in EoL scenarios. Kim et al. [10] formulated a BIM-based demolition waste estimation framework that is built upon the types of input construction materials. Based on the input materials, demolition waste output types were identified. Alwan et al. [56] proposed the Framework for Strategic Sustainable Development (FSSD) to assess the effectiveness of bottom-up zero-waste and zero-carbon approaches in the AECOO industry. Sanchez and Hass [65] established a BIM-based framework for adaptive reuse of buildings through selective disassembly sequence planning. Their method employs rule-based recursive analysis in order to find an optimal yet practical disassembly order for different building parts to minimise environmental impacts and cost performance of a building. Sanchez and Hass [38] further insisted that cost-benefit analysis is necessary before any construction or demolition to compare the associated environmental and economic costs with respect to new element installation alternatives. Furthermore, Rose and Stegemann [8] proposed a "triage process" to capture the information in the right time and make it visible in the right place within the community by direct reuse through creative usages in the existing building stock. Their study showed that one of the main deconstruction barriers is that valuable components are not identified in advance. BIM can solve this issue through virtual visualisation and monitoring of the components.

Bilal et al. [66] reviewed the top five BIM authoring tools on the market (namely Autodesk Revit, Bentley MicroStation, Graphisoft ArchiCAD, Vectorworks and Digital Project) to assess their ability to support construction waste reduction practices. They identified various features that are fundamental for a BIM-compliant waste minimisation software or plug-ins. Following that, BIM-enabled Building Waste Performance Analysis (BWA) is proposed by them in order to use BIM for designing out waste through building model analysis, waste predication, waste visualisation and, eventually, waste minimisation.

Furthermore, "Big Data" is another emerging trend that has attracted many researchers in every field of science. Tibaut and Zazula [67] proposed a conceptual and technical framework for the sustainable management of construction sites through big data. They tested their prototype for on-site waste monitoring during the construction phase as well as monitoring of the manufacturing and transportation of the components in off-site construction activities. An effective BIM-aided Artificial-Intelligence-enhanced monitoring of the construction works reduces the chances of rework and waste generation, which eventually results in high quality as-built BIMs. In another study conducted by Bilal et al. [11], Waste Analytics (powered by Big Data Architecture) were studied. 
They believed that waste analytics were the future of waste management in comparison with the Waste Intelligence that is practised in current waste management activities. They claimed that designing out waste (i.e., waste minimisation at the early design stage) is more compatible with waste analytics (WA) than with waste intelligence because WA is more data-driven and can handle a considerable volume of disaggregated construction datasets in order to find the latent patterns in the design, procurement and supply chain of materials [11]. They further argued that WA allowed for various advanced techniques (such as time-series analysis for forecasting and preventive purposes), which is the reasoning behind the mixture of WA and other techniques to create their waste simulation prototype. Their plug-in is built upon the Autodesk Revit's application programming interface (API) as the BIM tool and reportedly uses IFC for capturing design changes [11].

Akinade et al. [68] identified a gap considering the lack of existing BIM software capabilities in terms of EoL waste performance analysis, especially during the early design phases. Hence, they developed a mathematical model, called the BIM-based Deconstructability Assessment Score (BIM-DAS score). It provides an objective score for the assessment of the DfD strategies and the degree of deconstructibility of a building design. The BIM-DAS score can be separated into Deconstruction Score (related to building components) and Recovery Score (related to building materials). It can be linked with BIM tools to automatically retrieve information from a model.

For optimised deconstruction or renovation planning, Volk et al. [69] developed an innovative prototype called "ResourceApp". It records, stores and re-constructs the interiors of existing buildings and then it creates material inventories accordingly. Time, material and cost estimations are quickly done with this prototype. ResourceApp uses the analysed results of the sensors' data to detect objects via walk-through inspections. Then, the results are fed to BIM tools for creating a digital twin.

Consequently, the BIM-based Whole-life Performance Estimator (BWPE) tool was developed by Akanbi et al. [63] as a mathematical model to measure the degree of material circularity in the EoL phase. BWPE is a BIM-based building salvage performance estimator that aims to contemplate the sustainability of construction and deconstruction options to support the early-phase design decisions. The BWPE gives numerical values for the degree of material recoverability and their distribution reliability. It is compatible with BIM tools, since intelligent parametric modelling of BIM allows for automatic retrieval of error-free information about the quality and quantity of the materials and components in the model.

Furthermore, Lu et al. [70] added additional non-geometric properties to the properties of BIM components in their prototype for proper Construction Waste Management (CWM) estimation. The properties included design waste generation level, design waste amount, construction waste generation level and construction waste amount. The CWM information is accessible through an external database that can be linked with BIM or be added to the existing BIM components.

Liu et al. [39] developed the design of a decision-making BIM-aided Construction Waste Minimisation (Baw) framework based on a mixed methodology that uses the results of questionnaires, interviews and a literature review. The $\mathrm{BaW}$ framework intends to enhance communication, collaboration, document management, detailing and clash detection as well as waste minimisation performance to calculate the virtual waste in all design stages. The BaW Framework was set to meet the Level 2 and Level 3 BIM requirements and has two parts: High-level BIM-aided construction waste minimisation $(\mathrm{BaW})$ framework and Low-level BIM-aided construction waste minimisation $(\mathrm{BaW})$ framework. The former is for strategic decision-making and the latter helps with the detailed CWM processes and actions. High-level BaW is attuned with the high-level sustainability needs of clients, such as feasibility studies and decision-making assistance for strategic briefing development. Low-level BaW evaluates the concept design's virtual waste minimisation. It aims for an optimised design with the least virtual waste generation through 3D parametric modelling and clash detection. The result of the virtual waste analysis can be reported as the Waste-factor (i.e., the percentage of construction waste generation) [39]. 
A limitation of all these prototypes and frameworks is their use of proprietary BIM tools (mainly Revit) to demonstrate their successful implementation. Moreover, they have added properties (that are necessary for calculating their frameworks' indices as additional general properties without working on the potential specific properties that can be later adopted by the BIM tool vendors. For example, quality information, such as prefabrication and demountability of elements, was inserted into the model through Custom Parameters in Revit for the BWPE tool [63]. Therefore, a majority of solutions are firstly based on a specific API, which reduces the possibility of universal solutions. Secondly, the results of these studies are case-specific, which leads to arbitrary decisions that are not easily reproducible. Due to the combination of these factors, environmental or EoL assessment indicators that are developed are not necessarily compatible and comparable with each other.

\subsection{BIM and Life Cycle Assessment}

An increasing number of studies are leveraging BIM for LifeCycle Assessment (LCA), although most of them neglect the EoL phase in the whole lifecycle analysis [41]. Hossain and $\mathrm{Ng}$ [71] found that only $27 \%$ of BIM-based LCA studies considered the CDW generation during the construction, renovation and deconstruction phases. Different waste production factors are considered in different BIM-LCA and waste-generation studies, which limits the comparison of the results. For example, Won et al. [40] claimed that they did not consider the waste generated by formwork and packaging materials in their LCA analysis. Furthermore, Lockrey et al. [13] believed that LCA of waste streams should be performed separately but hand in hand with the LCA of material streams in order to find the critical materials in the construction.

One of the barriers that prevents the full adoption of BIM for LCA is that LCA is a data-intensive methodology [72]. LCA requires detailed information about building materials in order to assess their embodied impacts in various lifecycle stages. However, a "common language" must be utilised to facilitate the exchange of data between BIM and LCA inventories or LCA tools. This means that naming conventions and data structures must meet the specific needs of both BIM and LCA methodologies [72]. A robust ontology-based lifecycle energy inventory can also provide a consistent material data inventory for the supply chain of reusable materials [73].

Densley Tingley and Davison [20] benefited from BIM-LCA integration to investigate the LCA of reused materials, products and buildings, which were designed based on DfD guidelines. As a result of their methodology, the free web-based Sakura tool was developed. Sakura assesses various business-as-usual designs with DfD-based structural design alternatives in terms of the estimated embodied energy and carbon savings. They differentiated EoL scenarios for buildings and components since they believed that the environmental impacts of the reused materials could be shared between the number of anticipated lives in order to reduce the overall impacts [20]. In another study, Röck et al. [72] used a Revit-based BIM as a data source for LCA and reported their results as a spreadsheet-based library of potential construction options via Dynamo. Having a comprehensive building element database based on standard functional performance criteria (e.g., thermal and structural properties, service life, circularity and so forth) could significantly increase the use of LCA in the early design phase. On that note, LifeCycle Inventories (LCI) must become BIM-compliant. Providing an LCI for the designated system under assessment is time-consuming and automating it through BIM accelerates the decision-making associated with LCA. According to Peng [74], the shorter (and the earlier in the design phase) the time is that it takes to perform an LCA for building design, the better the design option comparison. Other benefits of having a unified inventory of materials are higher data quality and lower uncertainty [73].

Soust-Verdaguer et al. [43] found that obtaining the bill of material quantity from BIM is the most common application of BIM in case studies. However, if material passports or other environmental assessment information, such as Environmental Product Declaration (EPD) or Product Environment Footprint (PEF), are available in BIM or through BIM, then the automatic bill of material would not be the most important BIM usage. 
The number of BIM-based LCA studies in the new-construction building stock is higher than the existing building stock [43]. Nevertheless, these case studies are built upon the APIs of specific proprietary BIM tools and are developed in the forms of plug-ins that are linked with LCA software. Although they deliver immediate results, their exclusive tool dependency is a disadvantage and a temporary BIM-based bandage. Direct data exchange in BIM-LCA studies is not mature enough and these tools have remained disconnected so far. The flow of information is one-directional and passes through several bridging software/APIs before delivering any results [43,74]. As an example, a BIM-enhanced LCA methodology was developed by Ajayi et al. [75] in order to acquire the material specification for LCI from Revit by following a multi-step information exchange protocol.

BIM can help with extending the lifecycle of a building, since unfunctional components are easily detectable during the Operation and Maintenance phase. It also facilitates the change-of-use in occupancy or ownership; in other words, the management of future spatial changes [25,76]. Since there is no guarantee that the current standards and best practices are also acceptable in the future, the information stored in BIM helps with future decision-making. Additionally, facility management tools need to incorporate the status as well as the lifecycle history of building components in order to use this information for an effective EoL execution [51]. In asset management practices, it is difficult to update the lifecycle changes in a "space" with the traditional Computer-Aided Facility Management (CAFM) software. However, a direct link between an up-to-date digital twin and CAFM tools would solve this issue. Re Cecconi et al. [54] demonstrated such BIM and asset management integration in their study. Another problem is that the facility managers are not well trained with BIM. Therefore, they require simplified software for using BIM in their practice.

Furthermore, some BIM-LCA studies considered the emissions of the EoL phase. Marzouk et al. [77] studied the direct and indirect emissions of building elements, taking into account the deconstruction/demolition phase. They retrieved the information of various elements from BIM in order to calculate the total emission index for each alternative solution through a plug-in that they had developed. This index is saved in BIM for future references. Their methodology exemplifies cases in which BIM is treated as only a database. Their results showed that for decision-making about the waste generation in each EoL scenario, the amount of total emissions produced should be considered as well. Following that, the Environmental Building Information Modelling (EBIM) methodology was proposed by Marzouk et al. [78]. Through a road construction case study, the environmental impact indicators throughout the whole lifecycle of a built asset were addressed.

However, most of these studies used BIM for projects in which they had readily available digital twins. This raises several questions. How does one work on projects with no BIMs? How does one account for un-modelled elements in different design alternatives? Finally, how does one include intricate construction details when establishing a BIM-based LCI?

\subsection{BIM-Aided Waste Management}

Statistics show that construction waste has increased despite the efforts to reduce it [11]. The ultimate goal of deconstruction and DfD is to minimise the overall waste generation in the AECOO industry. Waste is categorised as Demolition Waste and Construction Waste, depending on the respective lifecycle phases that they are produced in. Therefore, some researchers have distinguished them, while others lumped them together as CDW (i.e., the total amount of waste generated during the building lifecycle). Up to now, no commercial or academic BIM solution has fully used BIM for CDW management [70], even though BIM can provide many benefits in this regard. Firstly, BIM offers an easy comparison between different design alternatives. For instance, Lu et al. [70] proposed a computational framework for CWM via BIM to assess the design options. In their framework, "information readiness" and "computational algorithms" play crucial roles in the stakeholders' understanding of the impacts of their decisions on the CWD generation. Their prototype calculates the possible amount of waste based on the Design-Bid-Build procurement model. It automatically obtains the quantities of a design or construction arrangements through BIM and maps them to the Waste Generation Rates database (WGR). 
Secondly, since design errors are reduced, rework and potential on-site waste generation complications are reduced as well. Thirdly, BIM can help designers in the early design phase to estimate the amount of waste in different lifecycle stages. Won et al. [40] compared the on-site "design-errors-induced" construction waste generation versus prevented waste due to BIM-based design in the two phases of pre-construction and construction. The volume of the prevented demolition waste was roughly 2.5 times the demolished volume, with a potential $1000 \mathrm{~m}^{3}$ of construction waste volume due to design errors. Fourthly, BIM increases the visibility and quality of existing physical assets as well as the remodelling changes [54]. Knowing the location and type of recyclables in a building facilitates the anticipation of the specific demolition/deconstruction methods.

Furthermore, Peng [74] considered the unsupported presumptions concerning the demolition of materials as a hindrance towards accurate estimation of environmental impacts of a building. Cheng and Ma [9] developed a BIM-based waste estimation system to obtain the volume of each element category and material type in Revit, as well as estimating the inert and non-inert wastes, disposal fees and the number of pick-up trucks for R\&D projects in the early design stages. Their study is amongst the very first applications of BIM for EoL planning [30]. A conceptual framework for lifecycle-based integrated CDW management is proposed by Yeheyis et al. [79], for which they have anticipated a Construction Waste LCA-based Sustainability Index (CWLSI). They developed a methodology to calculate the environmental, social and economic sub-indices for CDW decision-making assessment in relation to material selection, sorting, recycling, reuse and CDW treatment.

Subsequently, Rose and Stegemann [8] discovered a less-talked-about gap regarding the lack of knowledge of "under-used" elements for which environmental and economic improvements upon conventional recycling can be developed. De Magalhães et al. [80] investigated the construction waste generation in infrastructure projects by focusing on the main construction techniques associated with design typologies. On that note, the variations of locally available raw materials, climates and traditions have given variety to the typologies of buildings [71], which can lead to the diversity of possible deconstruction methodologies.

Secondary to the tangible environmental benefits of waste management, tracking and minimisation of waste through optimised design can lead to the adequate use of the construction residues. For instance, appropriately optimised cut-off lengths, areas and volumes of materials based on accurate BIM-based quantity take-off are investigated in [40] in order to reduce the construction residues. This is in contrast to the money and material wastages that come from improper cutting plans for reinforced steel bars or the excess amount of on-site concrete. In the same direction, mal-function or non-calibration of plants and equipment can also lead to waste generation [6].

\subsection{Materials/Components Bank}

The AECOO industry is moving towards a closed-loop supply chain business model [73]. Sanchez and Hass [38] debated that adapting reusable strategies will direct the market towards an "intelligent economy" instead of a resourced-based one. A group of components constitutes a single building; as such, their overall performance forms the environmental impact of the building. However, once the building is deconstructed, each component will have its individual EoL scenario and future impacts [20]. Considering that the possibility of the same group of components ending up in the same building together is rather low, therefore, they need a storage place before starting their next lifecycle within a new building. This makes the concept of a Materials/Components Bank (M/C Bank) inseparable from the deconstruction and DfD discussions. Cai and Waldmann [81] conceptualised the M/C Bank as a "manager" that regulates the transfer of materials from a building at its EoL phase to a new structure. Figure 5 demonstrates their concept of M/C Bank, as different sources of input material to the M/C Bank exist, which require appropriate actions such as DfD [81]. However, an M/C Bank is more than just a physical storage. A digital M/C Bank representation is needed to publicise the availability of the reusable elements to the market [37]. To be coupled with BIM, an M/C Bank must have a BIM-compliant digital representation—a database that contains suppliers' information and 
material specifications. BIM can enhance the material and product specifications directly and influence the prediction of waste performance targets, since the specifications can be linked with the available materials and components in the market [39]. However, a challenge is to use the material specifications from "reputable environmental databases" [56].

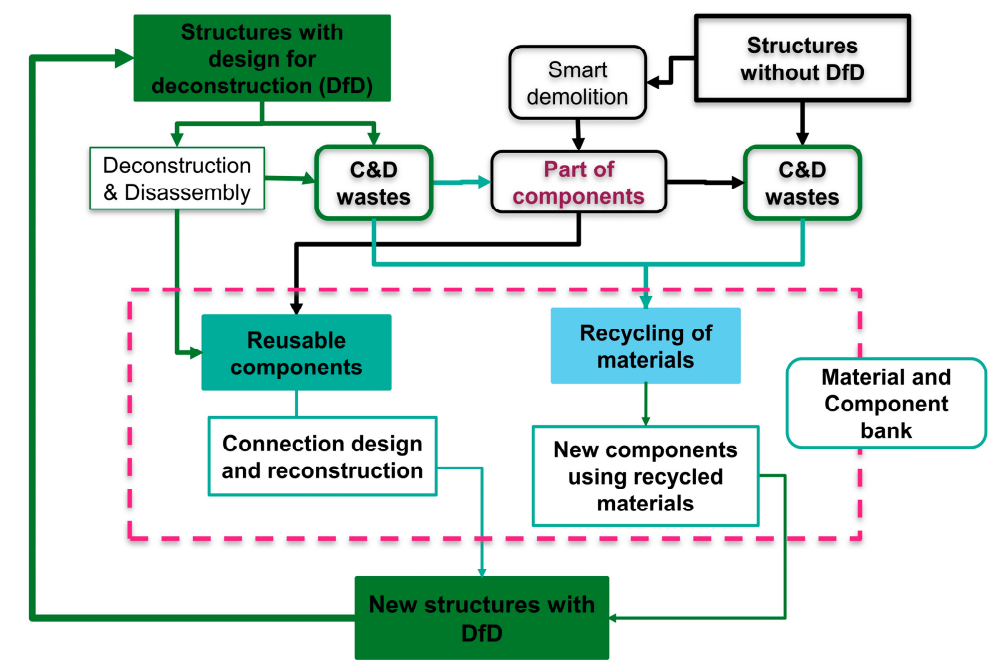

Figure 5. The interconnection between deconstruction, Design for Deconstruction (DfD) and secondary material streams with the Materials/Components Bank (M/C Bank), as conceptualised by Cai and Waldmann [81]. The figure is modified from [81].

Rose and Stegemann [8] believed that reusing the components will contribute to the development of component management systems, while Minunno et al. [73] regarded "cities as material banks" and "buildings as a material bank" as the construction industry's next stop in the zero-waste movement. Following that, Koutamanis et al. [82] reviewed the state-of-the-art of the feasibility of urban mining within the existing building stock, as well as the "cities as mines" concept. This is in line with Kohler's idea of "existing buildings as secondary resources" for resilience management of building stocks [17]. In his recommended principles for "resilience heuristics in the stewardship of building stocks", he suggested open information systems with redundant and distributed information and decision structures to create a balance between the material system (i.e., fabric) and the control system (i.e., management) within a building stock. Similarly, the European Commission's recently published circular economy principles for building design instructed that any change in the usage of building elements during a building's life must be recorded in a "building logbook" [29], although no further explanation is given.

From a technical perspective, such a logbook can be a BIM-compliant digital Distributed Ledger technology to connect interested buyers with reliable building material passports [73]. A distributed ledger records the transaction histories of digital assets [83]. One highlighted concern regarding the built asset information modelling is the authenticity of the user data, especially in electronic tendering [55]. Hence, the secure logging of digital entries has encouraged researchers toward a new cross-disciplinary trajectory for investigating the application of blockchain technology in the construction sector. Blockchain advocates believe that this technology can contribute to the trustworthiness of material quantities and secure logging of digital construction data entries through the whole lifecycle of a building [84]. Additionally, blockchain technology builds trust between parties that are unknown to each other, since the database of materials cannot be forged or damaged [85]. Any IT-enhanced construction workflow can benefit from the integration of blockchain and BIM to host or distribute IT-enhanced construction input and output (e.g., BIM-based digital material objects). The easy use or production of material passports can be enhanced due to BIM's capability for functioning as an information storage as well as its intelligence to reflect any change immediately [8]. 
A controversy in the $\mathrm{M} / \mathrm{C}$ Bank concept is the fact that some elements might have cosmetic problems, while others have acute problems. Hence, their reusability should be tested in terms of structural and environmental performance. On top of that, the storage conditions also affect performance and reusability. The longer the materials are kept in storage, the higher the potential for waste generation. For instance, improper storage and handling of materials might lead to their deflection, while fine aggregates, bricks and blocks could be lost if stored inadequately [6].

Aside from the health of physical materials in the M/C Bank, their digital records must be sound and secure. Since the information should be circulated between $\mathrm{M} / \mathrm{C}$ banks and many BIMs, the information exchange should be secure and tamper-proof as well. Minunno et al. [73] believed that smart contracts can protect the design information of buildings. Smart contracts are algorithm-based computer protocols with human-readable user interfaces that automate the traditional contracting process (i.e., terms and conditions), which results in functionally secure digital relationships [86]. They are backed by "Blockchain 2.0", which supports the decentralised and transparent history of transactions in a chain of blocks of information without a need for any trustworthy central authority [84]. Smart contracts also benefit from the distributed ledgers that were mentioned earlier [85]. Therefore, the legal issues concerning material passports, their trustworthiness and the secure and long-time storage of information might also be solved by smart contracts.

Going a step beyond the M/C Banks and the supply chain of reusable construction materials is the Geographic Information System (GIS) technology and its beneficial integration with the digital deconstruction through BIM, since the status and location of materials are reported in real-time $[38,87,88]$. However, there are some barriers in the complete integration of BIM and GIS that stem from their different modelling paradigms in terms of geometry, semantics and level of details [89]. Nevertheless, a successful case of BIM-GIS integration was employed by Al-Saggaf and Jrade [90] to facilitate demolition waste management by leveraging the distance measurements for truck loading and hauling. Such BIM-GIS-EoL synergy can improve waste logistics. The compounded data richness and visualisation capabilities of BIM and GIS also pave the way for smart cities and City Information Modelling (CIM) [87,88]. For instance, an Urban Information Model (UIM) extension was purposed by Mignard and Nicolle [91] as a "crossroad" between the BIM and GIS domains. They developed an ontology that accepts information from either IFC or CityGML in order for the ACTIVe3D platform to go from building facility management to urban facility management.

\subsection{BIM for Lean and Off-Site Construction}

Although not directly relevant to the EoL scenarios or DfD, our keyword criteria brought up some studies which concentrated on the integration of BIM and Lean Construction (LC) [92,93]. The reason could be that lean and parallel production have an inherent waste-minimisation nature, which makes LC a niche close to deconstruction [73,94]. Aziz et al. [92] considered "Lean" as not only the optimal use of the material resources, but also of time and human resources. However, in our limited number of papers, no standalone BIM-based LC prototype was found. Nascimento et al. [93] concluded that the integration of BIM and LC enables better decision-making by prioritising the usage of the material, workforce and technology resources in the project. This prioritisation, in turn, leads to waste reduction, quality improvement, error elimination, schedule optimisation, effective team collaboration and efficient interdisciplinary management. In principle, LC aims for lower waste and higher overall efficiency of a project. Mazlum and Pekeriçli [94] argued that the LC-based waste management studies are more focused on material loss and less on the "non-value adding works". However, they classified waste items based on the works of $[95,96]$ into over-production, over-processing, waiting, unnecessary transportation and motion, inventory excess, defects and even unused employee creativity. Moreover, in the 5D LC-based Bridge Information Modeling (BrIM) project by Giovanny Sanchez-Rivera et al. [97], the construction process was simulated, which resulted in a decrease in the occurrence of unforeseen events associated with lack of resources. 
Increased productivity and resourcefulness as a result of the systematic continuity are the engines behind the LC concept's development over the past years, both in theory and in practice. Hence, the close connection between BIM and LC is not a surprise. Lean construction and manufacturing benefit from the accurate design models and material quantities provided by BIM. Improved planning and scheduling and the just-in-time arrival of employees, machinery and construction resources are other valuable benefits of LC-BIM integration [26].

Concerning the lean production principles, Sacks et al. [98] created the BIM-enabled KanBIM Workflow Management System, which reduces the waste by establishing a stable workflow and encouraging higher collaboration. Moreover, Ma et al. [99] created an Integrated Project Delivery (IPD)-inspired collaboration platform. IPD stands for Integrated Project Delivery method. This method is used to increase the consistency of the project goals or deliverables through effective operation and consistent performance. Waste prevention is not the only outcome of their study, but also better collaboration towards higher client requirement satisfaction [99]. The IPD method fits perfectly with BIM methodology, since BIM facilitates integrated design and supports integrated teams [26]. In another example, the successful implementation of Mechanical, Electrical and Plumbing (MEP) prefabrication was studied by using BIM and IPD to involve contractors in the early design stage [100].

In addition to LC methods, Modular and Off-site construction favors standardised prefabricated modules for rapid on-site assembly in contrast to the traditional on-site construction [100]. This method rose to popularity after the scarcity of resources after World War II [101], although it is still a common practice because of its proven advantages for fast, affordable, easy-to-construct and repeatable construction, as well as its resource-saving potentials [73,100,101]. Prefabrication contributes to DfD by fostering the adaptability and reusability of components [73]. Prefabrication is widely favourable in the construction industry since it decreases the pressure of providing sustainable accommodation for the projected two-fold increase in the human population in the coming decades. Another benefit of prefabrication is the reusability of components due to their standard sizes, which is in line with the circular economy business model. Hence, standardisation of material types and sizes through prefabrication can contribute to the widespread application of M/C banks [73].

Furthermore, prefabrication enhanced by RFID (Radio Frequency Identification) sensors is among the heated topics in the AECOO research, which has not gained full adaptation in the industry. The barriers include high costs of equipping each element with an RFID sensor, as well as the concerns about the durability and complexity of the different modules. An RFID-enabled Building Information Modelling Platform (RBIMP) was proposed by Li et al. [44] to reduce the risks and errors through design, manufacturing and assembly of the prefabricated housing elements. BIM enhances the easy traceability of elements (or sensors) through its potential for storing and visualising information. Traceability is a feature that can enhance the EoL management. According to Ness et al. [61], unique RFID identifiers can be recorded in the IFC open format to contribute to the OpenBIM lifecycle information exchange. Further studies of the BIM-RFID technology combo where traceability (i.e., digital tracking) is useful for examining the steel reusability were performed by Densley Tingley et al. [37] and Ness et al [61].

\subsection{Interoperability and Industry Foundation Classes}

Lack of interoperability amongst BIM platforms on one hand and between BIM authoring tools and LCA, facility management, refurbishment and EOL tools on the other hand are strong themes in the literature $[43,44,54]$. Similarly, the loss of building lifecycle information is reported as a threat to the future of a sustainable and resilient building stock [17]. This calls for consistency in the storage and exchange of lifecycle information and points out the high importance of interoperability for digital deconstruction, since the latest status of materials and components must be accurately reported for reusability assessment and potential deconstruction. To make the data exchange situation worse, even if tools are interoperable, the variations in the data quality among many sources may pose problems for the integrity of the final model product. That is, if the data (for material specification and LCA) is available in the first place [74]. Hence, overall uncertainty and confusion about the current status of 
BIM in helping the EoL scenarios have to do as much as with the information modelling as they do with reusing the 3D model or the information in other EoL tools.

Although the keyword search criteria included the "Industry Foundation Classes (IFC)" keyword, few studies paid attention to IFC for EoL scenarios. Volk et al. [102] pointed out the role of BIM for demolition/deconstruction planning, as they studied the use of BIM for existing buildings. They elaborated a list of properties for possible IFC attributes that are to be addressed for any activity beyond the maintenance phase. Correspondingly, they identified the lack of unique Model View Definitions (MVDs) for any EoL alternatives. Industry experts believe that the IFC open schema is not equipped with adequate construction waste analysis and deconstruction processes or necessary IFC-based DfD data exchange requirements [103]. No IFC classes for DfD or deconstruction exist, which necessitates the development of IFC classes to support EoL scenarios and DfD [103]. BuildingSMART has several other standards besides IFC that allow the information exchange among platforms. These standards are also left out of the IFC-aided BIM-based EoL discussions. Therefore, it is worth it to look at the complementary relationship of these standards to support EoL scenarios and to work on their improvement in parallel. Nevertheless, if one of the project participants does not use BIM (e.g., because BIM is too complicated for them or does not have access to BIM tools) [54], then IFC can be as useful as a digital building model. It can be queried for relevant data with open-access software and does not need expert user knowledge.

IFC facilitates communication between building information models and platforms by providing standardised data. However, the building information models themselves must have equal and enough details to conform with BIM-based workflows or with external BIM-compliant databases, such as an $\mathrm{M} / \mathrm{C}$ bank. Hence, the appropriate Level of Development or Level of Detail (LoD) must be taken into account. LoD specifies the amount of graphical information that is required to be defined in the BIM, ranging from 100 to 550 . The higher the LoD, the higher the detail of each object, as can be seen in Figure 6. Liu et al. [104] stated that the right LoD for BIM during detailing ensures less on-site waste generation. Soust-Verdaguer et al. [43] believed that the most appropriate LoD for BIM-LCA projects is 300, since it represents objects in their actual sizes and details which are necessary to demonstrate the environmental impacts adequately. On that note, LoD 300 is also required for automatic quantity take-off from BIM. However, Kim et al. [10] advocated the use of higher LoD for EoL scenarios; once the volume is calculated, other sustainability measures related to demolition wastes can be calculated as well (such as the number of pick-up trucks). This argument should be further discussed, since the fabrication and assembly require LoD 400 and as-built BIM has an LoD of 500 inherently, since it is quite detailed. Therefore, if a building is going to be deconstructed based on an as-built BIM, then the precise information is needed. Hence, LoD 500 would be required. In the same vein, we would need at least LoD 400 for DfD (because many elements have assembly instructions). It can be concluded that for BIM-based deconstruction and BIM-based DfD, an LoD lower than 350 is not useful $[10,100]$. The appropriate Level of Information (LoI) should also be taken into account in cases in which the digital twin is not visualised in BIM tools, but instead in third-party software or web-based tools, such as open-source IFC viewers. This is because information and the properties of the objects are the centres of attention, not the visualisation or the geometric attributes. 


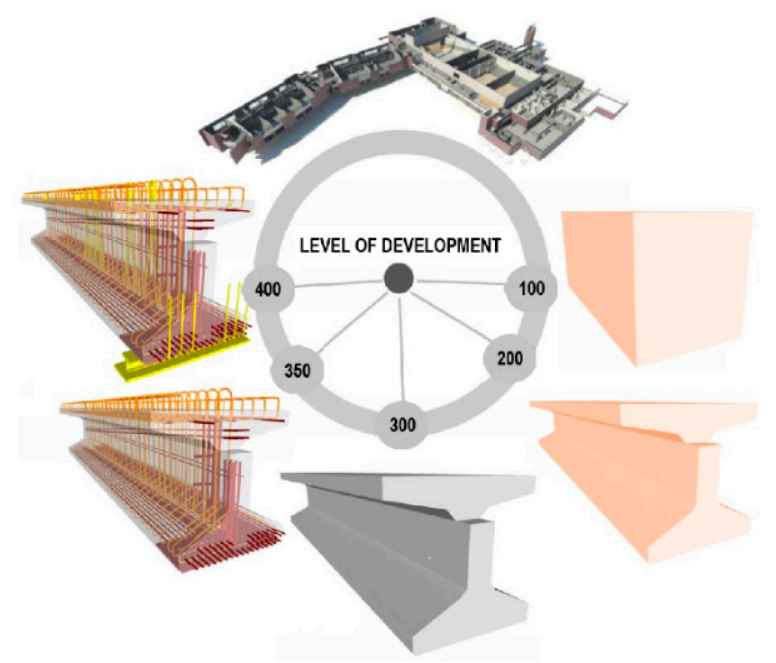

Figure 6. Level of Development (LoD). The image is taken and modified from [105].

\section{Discussion}

It was established through the literature review that even though digitalisation of workflows would reduce the amount of waste generated (whether on-site or off-site), the human factors and cultural attitudes that remain unaffected by digitalisation would result in some waste. BIM automates the task and enhances collaboration and communication through systematic document management [39]. As a result, project efficiency is increased while time and human resource wastes are reduced. These BIM advantages assist decision-makers in choosing the appropriate EoL scenario in a more informed manner through virtual models and reliable data. However, BIM is usually developed by one party and is handed over and used by other parties that do not have as detailed of a knowledge of the information inside the model as the primary BIM modellers. Thus, to support the different uses of BIM by an owner during the whole lifecycle (especially in EoL), a consistent plan must be developed for BIM hand-over to other stakeholders [52,53].

Regulations surrounding BIM-based EoL seem to be lax, since this is a new cross-disciplinary topic in the industry. In cases where solid regulations exist, they target the local construction market. The different natures of regulations between BIM and waste minimisation activities might lead to low uptake of BIM-based EoL and should be further studied. For example, most waste minimisation regulations seem to be market-based (having incentives or penalties set by the government), while if BIM is mandated in a country, then the regulations are of a command and control nature (the government provisions mandatory behaviour). The variations in the natures of these regulations should be clarified to set regulations for BIM-based EoL properly.

Despite several well-defined but ad hoc solutions, there is no globally acceptable BIM-based EoL solution. It is not clear whether this lack emanates from the absence of an EoL framework or the technological limitations of BIM. Although BIM offers some new opportunities, it has some constraints. No commercial or open-source BIM tool encompasses built-in options to integrate the EoL scenarios and their required properties. Due to this lack, a recurring pattern was observed in the studies in which the user-defined properties had to be added to the model in order to enable BIM tools to connect with external databases for EoL activities and M/C banks [66]. For instance, custom attributes were added to "each" component in BIM regarding the DfD/CWM/deconstruction possibilities.

Furthermore, the name selection for the attributes varies in different studies, as each study targeted a specific part of the EoL scenarios and had developed specific indices to report on the effectiveness of the given scenario. For instance, Akbarnezhad et al. [62] assigned a "recommended deconstruction method" attribute to their components in Tekla Structures, while Akinade et al. [68] and Akanbi et al. [63] used the "custom parameters" option in Revit for adding quality information such as "prefabrication" and "demountability". Following that, Re Cecconi et al. [54] suggested the 
possibility of using IFC attributes instead of custom parameters in the future. So far, no IFC class exists for EoL or CWM activities, nor does the proper MVD or any other relevant buildingSMART standard. This gap has also been mentioned by Volk et al. [102], which brings forward an excellent opportunity for future studies. IFCs nurture the open BIM ecosystem and normalise the quality of data distributed between parties. Moreover, the suitable data quality for a BIM-based deconstruction and BIM-based DfD is not clearly defined in the literature. Likewise, unspecified LoD and properties are reportedly hindering the BIM-based deconstruction projects [102]. By choosing the appropriate LoD and LoI for the BIM project, the necessary data can be used in future deconstruction activities. However, based on our review, an LoD of at least 350 is required to initiate any EoL planning. However, because of the data of the maintenance phase, a higher level of LoD could eventually be required.

In the studies that we reviewed, BIM is placed in one of the intermediate steps of the framework by only playing the role of a material repository. However, speculations exist regarding the future of the model once the building is thoroughly deconstructed, since the information about the first life of individual building components must be kept. This could justify the need for reusable material banks (i.e., M/C Banks). Information can be temporarily or permanently kept in an M/C Bank and moved to the new building's BIM should it be required [10]. However, at the end of the lifecycle of a building, a massive amount of information is stored in BIM (or is linked to BIM); therefore, a considerable amount of digital storage and processing power should be provided [10]. According to Liu et al. [39], it is better to discuss the requirements concerning model ownership and responsibilities, BIM input and output and BIM database structure and its components before the conceptual design stage.

What distinguishes DfD and deconstruction is that DfD has to be implemented in the early design phase, while deconstruction can only be executed at the end of an asset's lifecycle. In addition, DfD requires the foresight of all stakeholders, but deconstruction is bonded to the effectiveness of the few remaining stakeholders at EoL phase. However, some authors discuss the outcomes of deconstruction (and the possibility of reusing the disassembled components) simultaneously with DfD, as it seems that the key concepts are floating between DfD and deconstruction. The borderline between these two topics is thin and it appears that a "chicken or egg" causality is present in the deconstruction and DfD research questions. It is not clear whether the DfD requirements must be set first to guide the deconstruction requirement, or if it is the other way around.

The current building stock is not entirely suitable for deconstruction, since it was not built for this purpose. Therefore, even if the only viable option were to deconstruct the existing building stock, not many materials or components would be retrieved from this stock that can be reused. It is beyond the scope of this article to investigate the conditions with which elements are allowed to be reused after deconstruction. However, the lack of existing deconstructed/reusable materials might discourage engineers and architects from integrating the reusable components in their new designs. In the current construction market, this could mean that even if the new building design is DfD-based, the building elements are all sourced from new materials. However, to have a DfD-based building stock with reusable components, as would be the ideal case, several generations of building stocks must pass; a period of roughly half of a century would be needed to have a DfD-based building stock with reusable components embedded in it.

A lack of time-wise perspective on the BIM-based EoL constantly appears in the literature. Despite the concerns regarding the future-proofing of buildings and the embedded elements, it is not clear when these deconstruction strategies are going to be implemented. How far in the future are we thinking about? Certainly, strategising for the next 5 to 10 years is considerably different from the next 25 to 50 years due to the increasing technological progress in the construction industry and its imprint on the future economy, as well as the consequences of climate change on the planet. Clarifying a timeline for the possible implementation of BIM-based deconstruction frameworks is essential for the uptake of BIM-based EoL.

It is worthy to assess the existing building stock to provide feasible BIM-based EoL solutions. The majority of existing buildings in Europe that are close to their EoL phase were built in 
masses after World War II. This would imply two generations of deconstruction activities: Firstly, the soon-to-be-deconstructed existing buildings with all of their traditional (and sometimes hazardous) materials and technologies and secondly, the designed-to-be-deconstructed buildings that are based on zero-waste integrated sustainable designs. The point is that the planning and execution of deconstruction would be different for these two different generations, while the salvaged materials and components are also vastly different. Since many materials and components in the existing building stock are not suitable for reuse [73], a strategy for the first generation of deconstruction activities could be to plan for recyclability of materials within the current building stock. Similarly to the mass construction after World War II, there could be possible mass deconstruction or mass demolition scenarios. Therefore, the possibility of having deconstruction typologies can be further investigated. The anticipation for mass deconstruction scenarios would justify the $\mathrm{M} / \mathrm{C}$ Bank enthusiasm within the industry.

Van Nederveen and Gielingh [25] pointed out the designers' need to reserve their desired element (in a material database), which can provide some considerations regarding the DfD-based design process with the assumption of having access to a fully functional M/C bank. Two ways can be proposed for the use of an M/C bank for the DfD practices. Firstly, in the "Design First, Bank Second" approach, after the design is finished, designers look in the $\mathrm{M} / \mathrm{C}$ bank for materials and components that are suitable for their design. In this manner, designs can be either flexible enough or optimised so that the selected reusable elements can seamlessly fit into them [41]. Alternatively, in the "Bank First, Design Second" approach, designers first look into the M/C Bank, choose some of the elements and then they start the design while having those elements in mind. In this approach, they should reserve their desired materials/components in order to secure them until the end of the project. Otherwise, if those components are taken out of the $\mathrm{M} / \mathrm{C}$ bank by another designer, then they have to redesign their project [25]. The lack of robust theoretical frameworks seems to impede a practical or technologically backed $\mathrm{M} / \mathrm{C}$ bank development. Although this topic is more connected with the early design phase, it casts a shadow on the tendering and procurement processes, which could be a direction for future researchers. Nevertheless, other unanswered questions exist that concern the possibility and nature of the communication of $\mathrm{M} / \mathrm{C}$ Banks and buildings through BIM during the operation and maintenance phase. Should owners or facility managers announce the decommissioning of the building to the M/C Bank in advance? Alternatively, who is responsible for making decisions about when the service life is over and when the building is going to be deconstructed?

Densley Tingley and Davison [20] raised an issue about the modularity of the distribution of environmental impacts of the materials in their first, second and third lifecycles. When a component with a lifespan longer than that of its embedded building is being reused, the environmental impacts of the first buildings could be reduced, as the impact is divided by the number of lifetimes. On that note, a case can be made for a keyword that seems to be missing in the literature to describe a DfD-based building with once-deconstructed elements. While DfD suggests that the building is eligible for deconstruction and its elements can be reused in the future, it cannot be said that DfD-based building designs have any necessity to be built with once-deconstructed (i.e., reusable) elements. Therefore, in order to discuss DfD and deconstruction in tandem, new keywords to describe the nuances of different types of buildings are needed. Therefore, a complementary concept to the $\mathrm{M} / \mathrm{C}$ bank, such as the "design with reusable materials" strategy, is also required to complete a closed-loop material design. Figure 7 illustrates a schema of a material loop in which building elements are subjected to EoL-based actions to circulate through the digital locations (i.e., BIM and M/C Bank). To move an element from the M/C bank to a new BIM, the new building needs to be designed with considerations for reusable materials as well as DfD. 


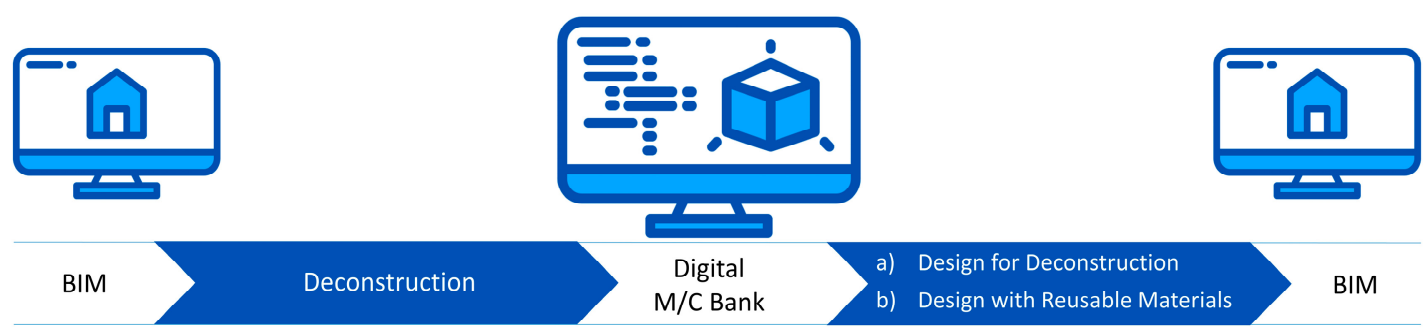

Figure 7. The circulation of materials to and from digital locations (i.e., BIM and Digital M/C Bank) through EoL-based actions (i.e., deconstruction, DfD and design with reusable materials).

Following that, another significant point in our review is that the investigated case studies with various BIM-based EoL objectives were all narrowed down to normally designed buildings, not DfD-based designed buildings. Hence, future studies can compare the results of the proposed BIM-based EoL frameworks for normally-designed buildings and DfD-designed buildings. In addition to that, the topic of deconstruction is mentioned in several studies hand in hand with renovation in terms of waste production $[9,41,69]$, but there seems to be no comprehensive research on BIM-based renovations and waste generation that could be investigated in future.

Many studies discussed waste management, waste reduction and deconstruction strategies simultaneously, although they differ. The former considers the waste produced in pre-construction, construction and deconstruction phases [41], while deconstruction, as the name suggests, is focused on this EoL phase. Causation exists between these two topics. The waste reduction would be a side effect of the deconstruction, but deconstruction cannot be the cause of waste reduction activities.

Finally, few articles considered the EoL of infrastructure. Although construction techniques between, for instance, a bridge and a building are similar, the types of joints, elements, the lifespans and the loadings pose different critical questions for the reusability and post-first-lifecycle assessment tests. Likewise, the deconstruction processes and technologies, as well as BIM-based infrastructure EoL considerations, could be different between structures and infrastructure.

\section{Conclusions}

The BIM-based EoL research domain is a nexus of three trending topics in the construction industry; digitalisation, sustainability and the circular economy. This research will serve as a base for future studies by providing an overview of the BIM-based EoL research domain to extend the understanding of its current status, existing issues and knowledge gaps. However, a limitation of our study is its dependency on the strict keyword search rule defined to retrieve the English-language peer-reviewed articles published between 2009 to February 2019.

Seven main academic research directions were found to be related to the BIM-based EoL domain, including social and cultural factors, BIM-based DfD and BIM-based deconstruction frameworks, BIM-based EoL within LCA, BIM-aided waste management, $\mathrm{M} / \mathrm{C}$ banks, off-site construction, interoperability and IFCs. Although some of these themes are not directly related to EoL scenarios and waste minimisation efforts, they are complementary topics that support efficient EoL decision-making and preventive waste generation activities.

BIM helps with more transparency, which increases the collaborative spirit in a construction project and helps with clearly defining the EoL responsibilities in decision-making and execution. Additionally, the automation of tasks through BIM reduces waste due to design-errors and can offer a useful comparison between EoL alternatives. As a result, the on-site and off-site human-made errors would be reduced.

BIM also retains the first lifecycle history of materials and components and exchanges this information with an $\mathrm{M} / \mathrm{C}$ Bank. However, no clear guideline for a feasible $\mathrm{M} / \mathrm{C}$ bank exists. This is a hindrance in the uptake of using reusable elements in the design. The mechanism which enables 
designers to design for deconstruction and simultaneously benefit from an $\mathrm{M} / \mathrm{C}$ bank must be clearly communicated. A fundamental question is whether to first design flexibly and then to choose reusable elements in the $\mathrm{M} / \mathrm{C}$ bank (i.e., design first, bank second approach), or to reserve the elements in an $\mathrm{M} / \mathrm{C}$ bank and then design based on their exact dimensions and performances (i.e., bank first, design second approach). To this aim, BIM-M/C bank integration protocols should also become apparent.

Another uncertainty concerning $\mathrm{M} / \mathrm{C}$ banks is the condition of the reusable elements. The deconstruction activities, as well as the storage conditions, affect the sustainable and structural performances of these components, which is another direction of research worth pursuing. Deconstruction is an activity that is envisioned to be fulfilled in an unknown future, although a specified period (i.e., building's service life) can be defined. This has created many uncertainties in defining strategies and frameworks. Currently, there are a number of BIM-based deconstruction frameworks, although they are limited to local construction regulations and are ad hoc solutions. Moreover, most of the studies focused on buildings; further investigation of infrastructure can also map the valuable components that can be salvaged or reused.

Although some might argue that EoL scenarios must be treated locally due to the variations in the construction typologies and input materials, a globally acceptable BIM-based EoL framework can accelerate the adoption of the sustainable and circular EoL scenario selection. Thus, comprehensive BIM-based EoL frameworks, together with deconstruction typologies parallel to the construction typologies, would help to resolve this issue, e.g., on a European level.

In the current building stock, many materials are not suitable for reuse, although they can be deconstructed. One reason is that they were not designed for deconstruction. Deconstruction and DfD are closely linked together, which has created some uncertainty in the literature. Although scientists discuss these topics altogether, it is not clear whether DfD-based designs should encourage the uptake of deconstruction in the industry, or the deconstruction and the availability of reusable components should encourage the DfD-based designs. This is a gap, as no BIM-based EoL study has investigated the application of BIM for a building which is not only DfD-based, but also constructed with reusable components. On that note, a natural flow of materials between deconstruction activities to an $\mathrm{M} / \mathrm{C}$ bank or to a DfD-based building can be envisioned. However, we suggest that researchers differentiate between BIM-based deconstruction and BIM-based DfD, since each focuses on a different lifecycle stage.

Nevertheless, the literature review revealed that EoL is not supported in any form by the available BIM tools on the market. This limits the BIM-based EoL decision-making frameworks/prototypes and makes them utterly dependent on a particular proprietary BIM tool. As a result, they are further limited in capturing all necessary EoL attributes that require adding custom parameters to record EoL information in the model. Therefore, all of these prototypes, plug-ins, or frameworks deliver a different deconstructability score or variable that makes them incomparable with each other.

Furthermore, the disconnection between BIM tools and EoL tools, CWD waste management tools and LCA tools is strongly emphasised in the literature. Correspondingly, no IFC protocols or MVDs to cover the EoL activities, requirements and communications exist. This further limits the open data exchange between BIM tools and external EoL tools, as well as material databases. Regardless of these exchange barriers, some authors suggested the use of BIM-complaint distributed ledgers and smart contracts to ensure the security of the lifecycle information of the reusable materials. Similarly, the LoI and LoD of BIM-based EoL were discussed in the literature. Based on our review, an LoD of at least 350 is required to enable the seamless exchange of information between BIM-based DfD, BIM-based deconstruction and BIM-compliant M/C bank frameworks.

Overall, BIM-based EoL is an emerging science front in the BIM research that has a huge potential to propel our society towards a more sustainable and circular future, in which cities and buildings are regarded as urban mines with valuable materials to be further reused.

Author Contributions: A.A. and F.N.T. conceptualised the study. A.A. investigated and prepared the original draft, while F.N.T. supervised it. L.B.J. and D.W. constructively reviewed and edited the manuscript. All authors have read and agreed to the published version of the manuscript. 
Funding: This research is a part of the ECON4SD (Eco-construction for Sustainable Development) project that has received funding from Investissement pour la Croissance et l'emploi-European Regional Development Fund (2014-2020), with grant agreement 2017-02-015-15.

Acknowledgments: The authors would like to thank the three anonymous reviewers for their constructive feedback.

Conflicts of Interest: The authors declare no conflict of interest.

\section{Appendix A}

The search rule criteria used for retrieving articles to review the state of the art of BIM-based EoL research is illustrated in Figure A1. A scientometric and bibliometric analysis was carried out using the bibliometrix package in RStudio based on the downloaded metadata of publications that matched the keywords. The complete results of this analysis are reported in Part 1 of Reference [30].

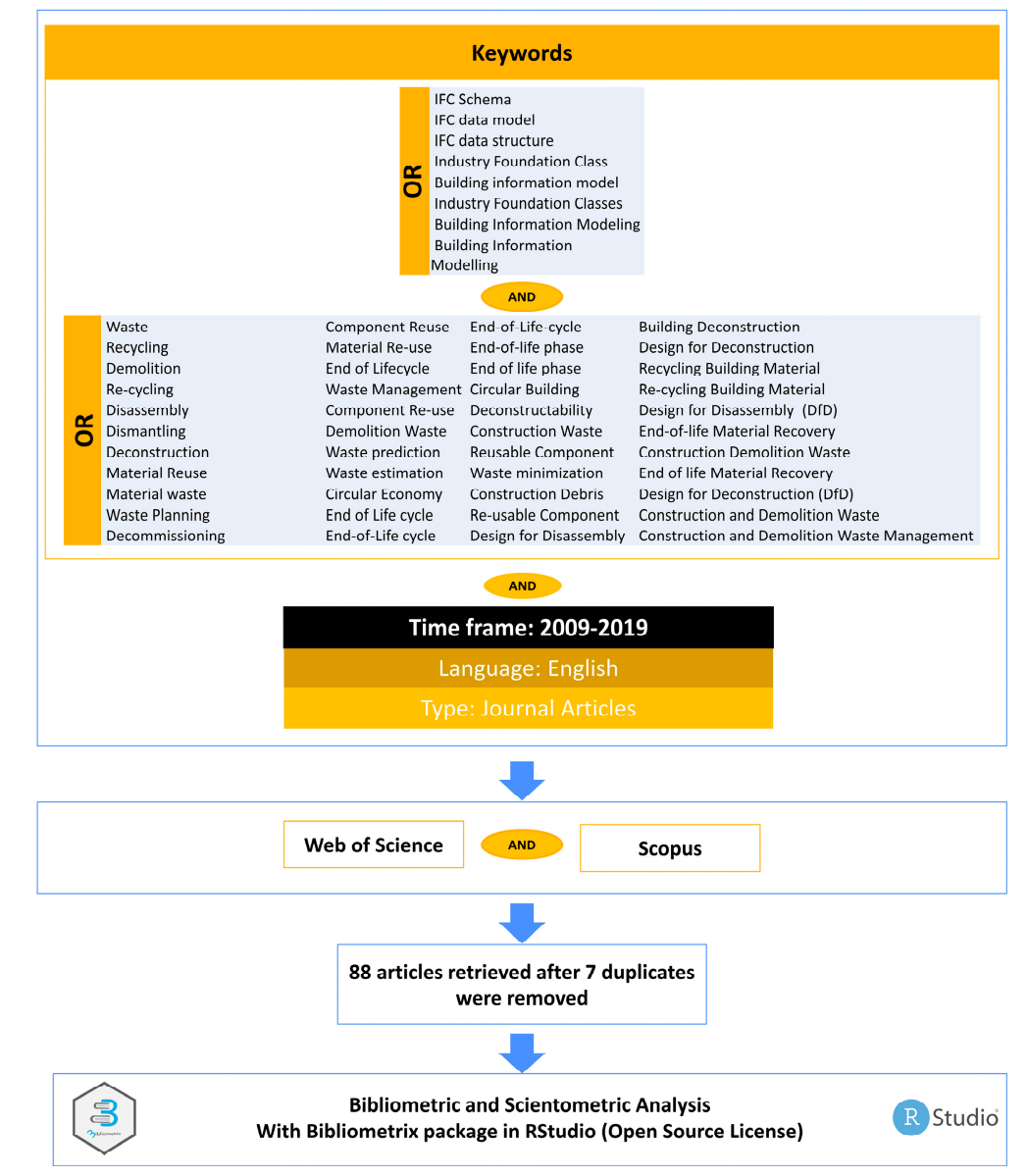

Figure A1. Search rule criteria used in the first part of the study to retrieve the metadata of the English journal articles between 2009 to February 2019 from the Scopus and Web of Science publishing databases. The figure is reproduced based on [30]. 


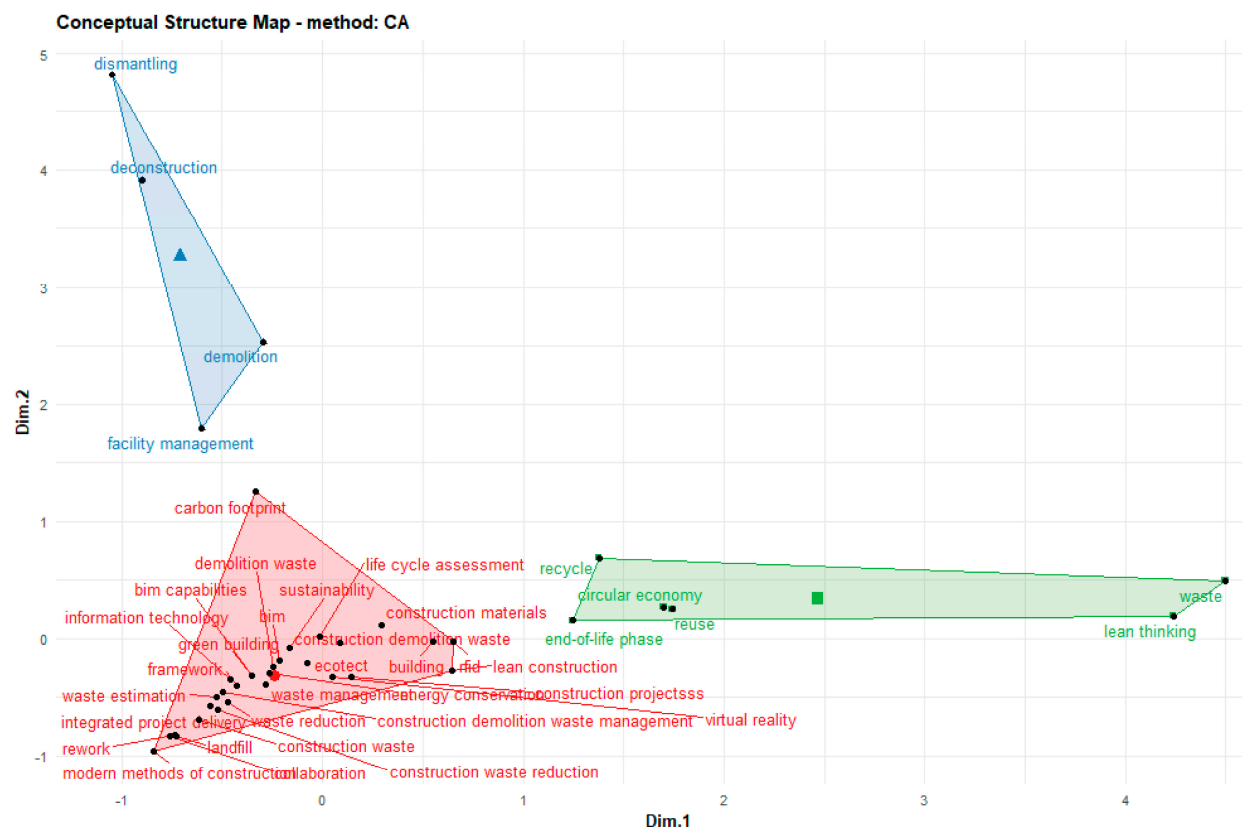

Figure A2. The Conceptual Structure Map of author keywords shows the keyword clusters that are conceptually related based on the Correspondence Analysis (CA). The figure is taken from [30].

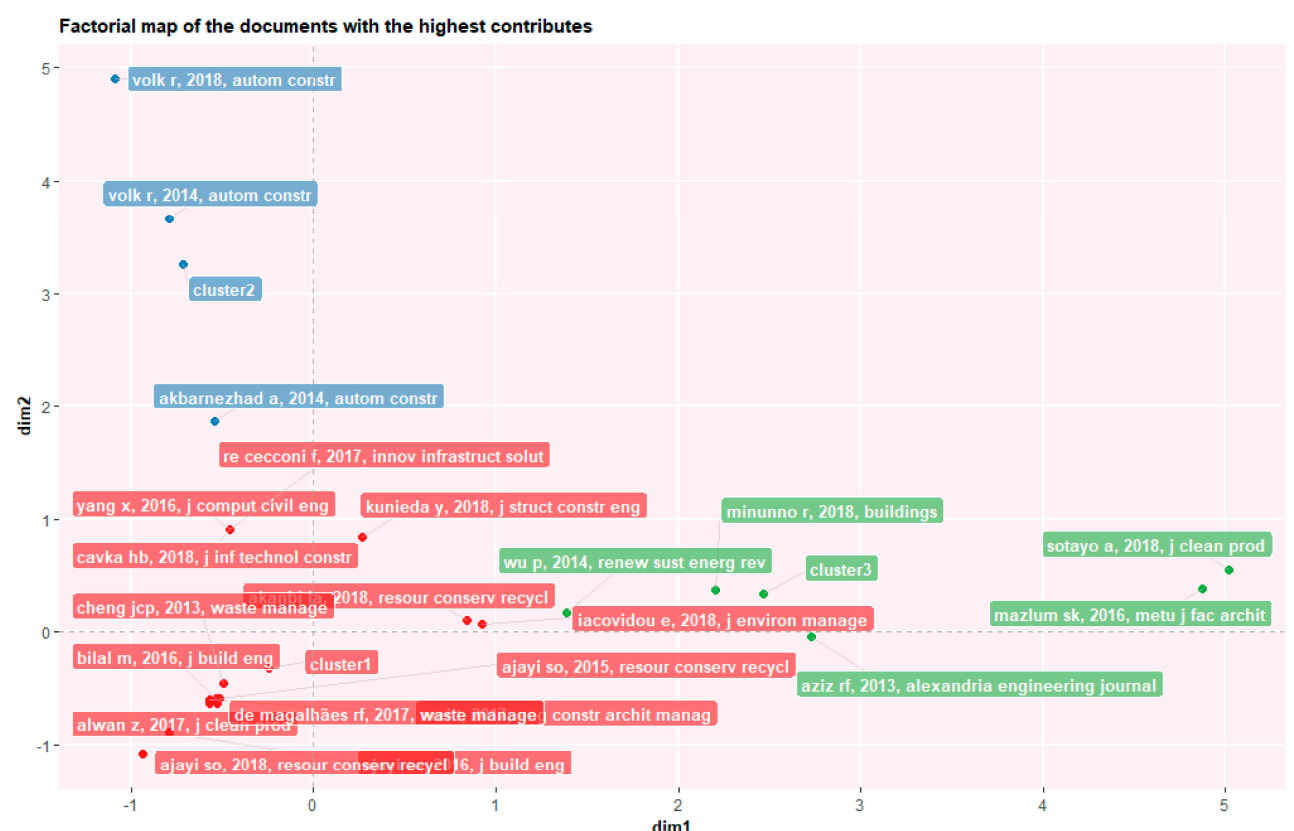

Figure A3. The Factorial Map of the articles with the highest contributions to BIM-based EoL research. This plot is superimposed on the Conceptual Map. The colours of the articles indicate the contributions of those articles to the development of keywords associated with the same colour on the conceptual map. The figure is taken from [30].

One of the main results of bibliometrics and scientometrics is the "Co-word" or "Keyword Co-occurrence" analysis. Co-word analysis reveals the relationship between concepts (i.e., keywords) based on their co-occurrences. As a result, the conceptual map of a research front is drawn in the first step, which gives insight into the progression of knowledge and the research hotspots. Higher co-occurrences of two keywords indicate that they are often mentioned alongside each other in publications, implying that they are closely related topics [31]. In the second step, the factorial 
maps are derived from the conceptual maps. Factorial maps demonstrate the positions of articles that are pinned to their corresponding author-selected keywords on the conceptual maps through factors that link keywords to individual publications [106]. This technique quickly discloses the publications that have significantly contributed to the development of specific keywords (or concepts) within the conceptual structure of a research domain.

Figures A2 and A3 are adopted from the first part of Reference [30]. Figure A2 illustrates the clusters of keywords and the focal points of researchers in BIM-based EoL so far. Furthermore, based on Figure A3, we started our critical literature review. We initiated by reviewing the top contributing publications and moved towards the rest of the articles later in our review.

\section{References}

1. European Commission. Communication from the Commission to the European Parliament, the Council, the European Economic and Social Committee and the Committee of the Regions-Roadmap to a Resource Efficient Europe COM (2011) 571 Final; European Commission: Brussels, Belgium, 2011; p. 26.

2. European Commission. Communication from the Commission to the Council, the European Parliament, the European Economic and Social Committee and the Committee of the Regions-A Lead Market Initiative for Europe COM (2007) 860 Final; European Commission: Brussels, Belgium, 2007; p. 11.

3. European Commission Construction and Demolition Waste (CDW). Available online: http://ec.europa.eu/ environment/waste/construction_demolition.htm (accessed on 5 February 2019).

4. Manfredi, S.; Pant, R. Supporting Environmentally Sound Decisions for Construction and Demolition (CED) Waste Management-A Practical Guide to Life Cycle Thinking (LCT) and Life Cycle Assessment (LCA); Publications Office of the European Union: Luxembourg, 2011.

5. OECD. Material Resources, Productivity and the Environment; Green Growth Studies; OECD Publishing: Paris, France, 2015; ISBN 978-92-64-19050-4.

6. Seethapathy, S.; Henderson, J.H. Management of construction waste in nuclear and thermal power plant projects in India. J. Constr. Dev. Ctries. 2017, 22, 19-46. [CrossRef]

7. Ajayi, S.O.; Oyedele, L.O.; Akinade, O.O.; Bilal, M.; Owolabi, H.A.; Alaka, H.A.; Kadiri, K.O. Reducing waste to landfill: A need for cultural change in the UK construction industry. J. Build. Eng. 2016, 5, 185-193. [CrossRef]

8. Rose, C.M.; Stegemann, J.A. From waste management to component management in the construction industry. Sustainability 2018, 10, 229. [CrossRef]

9. Cheng, J.C.P.; Ma, L.Y.H. A BIM-based system for demolition and renovation waste estimation and planning. Waste Manag. 2013, 33, 1539-1551. [CrossRef] [PubMed]

10. Kim, Y.-C.; Hong, W.-H.; Park, J.-W.; Cha, G.-W. An estimation framework for building information modeling (BIM)-based demolition waste by type. Waste Manag. Res. 2017, 35, 1285-1295. [CrossRef]

11. Bilal, M.; Oyedele, L.O.; Akinade, O.O.; Ajayi, S.O.; Alaka, H.A.; Owolabi, H.A.; Qadir, J.; Pasha, M.; Bello, S.A. Big data architecture for construction waste analytics (CWA): A conceptual framework. J. Build. Eng. 2016, 6, 144-156. [CrossRef]

12. Hoxha, E.; Habert, G.; Chevalier, J.; Bazzana, M.; Le Roy, R. Method to analyse the contribution of material's sensitivity in buildings' environmental impact. J. Clean. Prod. 2014, 66, 54-64. [CrossRef]

13. Lockrey, S.; Verghese, K.; Crossin, E.; Nguyen, H. Concrete recycling life cycle flows and performance from construction and demolition waste in Hanoi. J. Clean. Prod. 2018, 179, 593-604. [CrossRef]

14. European Union. Directive 2008/98/EC of the European Parliament and of the Council of 19 November 2008 on waste and repealing certain Directives; Official Journal of the European Union: Luxembourg; Available online: https://eur-lex.europa.eu/legal-content/EN/TXT/HTML/?uri=CELEX:32008L0098\&from=EN (accessed on 3 April 2019).

15. Zanni, S.; Simion, I.M.; Gavrilescu, M.; Bonoli, A. Life cycle assessment applied to circular designed construction materials. Procedia CIRP 2018, 69, 154-159. [CrossRef]

16. European Commission. EU Construction \& Demolition Waste Management Protocol Defines C\&D Waste; European Commission Directorate-General for Internal market, Industry, Entrepreneurship and SMEs: Brussels, Belgium, 2016; p. 52. 
17. Kohler, N. From the design of green buildings to resilience management of building stocks. Build. Res. Inf. 2018, 46, 578-593. [CrossRef]

18. Waldmann, D. Demountable Construction Enables Structural Diversity. Available online: https://orbilu.uni. lu/handle/10993/31437 (accessed on 29 January 2020).

19. Simion, I.; Ghinea, C.; Maxineasa, S.; Taranu, N.; Bonoli, A.; Gavrilescu, M. Ecological footprint applied in the assessment of construction and demolition waste integrated management. Environ. Eng. Manag. J. 2013, 12, 779-788.

20. Densley Tingley, D.; Davison, B. Developing an LCA methodology to account for the environmental benefits of design for deconstruction. Build. Environ. 2012, 57, 387-395. [CrossRef]

21. European Commission. Report from the Commission to the European Parliament, the Council, the European Economic and Social Committee and the Committee of the Regions-on the Implementation of the Circular Economy Action Plan COM (2019) 190 Final; European Commission: Brussels, Belgium, 2019; p. 12.

22. European Commission. Communication from the Commission to the European Parliament, the Council, the European Economic and Social Committee and the Committee of the Regions-Closing the Loop-An EU action Plan for the Circular Economy COM (2015) 614 Final; European Commission: Brussels, Belgium, 2015; p. 21.

23. Durmisevic, E. Transformable Building Structures: Design for Dissassembly as a Way to Introduce Sustainable Engineering to Building Design \& Construction. Ph.D. Thesis, TUDelft, Delft, The Netherlands, 2006.

24. Durmisevic, E. Circular Economy in Construction Design Strategies for Reversible Buildings. Available online: https://www.bamb2020.eu/wp-content/uploads/2019/05/Reversible-Building-Design-Strateges.pdf (accessed on 29 January 2020).

25. Van Nederveen, S.; Gielingh, W. Modelling the life-cycle of sustainable, living buildings. Electron. J. Inf. Technol. Constr. 2009, 14, 674-691.

26. Sacks, R.; Eastman, C.; Lee, G.; Teicholz, P. BIM Handbook: A guide to Building Information Modeling for Owners, Managers, Designers, Engineers and Contractors, 3rd ed.; Wiley: Hoboken, NJ, USA, 2018; ISBN 978-1-119-28755-1.

27. Chatterton, S. The BIM Jedi (Formally the Revit Jedi): The Many Dimensions of BIM. Available online: http://bim4scottc.blogspot.com/2018/01/the-many-dimensions-of-bim.html (accessed on 5 February 2019).

28. Charef, R.; Alaka, H.; Emmitt, S. Beyond the third dimension of BIM: A systematic review of literature and assessment of professional views. J. Build. Eng. 2018, 19, 242-257. [CrossRef]

29. European Comission. Circular Economy-Principles for Building Design; European Comission: Brussels, Belgium, 2020.

30. Akbarieh, A.; Jayasinghe, L.B.; Waldmann, D.; Hjaltadóttir, R.E.; Teferle, F.N. BIM-based end-of-life cycle decision making and digital deconstruction: Scientometric and bibliometric analysis. Sustainability 2020, in press.

31. Aria, M.; Cuccurullo, C. bibliometrix: An R-tool for comprehensive science mapping analysis. J. Informetr. 2017, 11, 959-975. [CrossRef]

32. Cobo, M.J.; López-Herrera, A.G.; Herrera-Viedma, E.; Herrera, F. An approach for detecting, quantifying, and visualizing the evolution of a research field: A practical application to the fuzzy sets theory field. J. Informetr. 2011, 5, 146-166. [CrossRef]

33. Hood, W.; Wilson, C. The literature of bibliometrics, scientometrics, and informetrics. Scientometrics 2001, 52, 291-314. [CrossRef]

34. RStudio Team. RStudio: Integrated Development for R; RStudio, Inc.: Boston, MA, USA, 2016.

35. Wang, N.; Liang, H.; Jia, Y.; Ge, S.; Xue, Y.; Wang, Z. Cloud computing research in the is discipline: A citation/co-citation analysis. Decis. Support Syst. 2016, 86, 35-47. [CrossRef]

36. Nisonger, T.E. The "80/20 Rule" and core journals. Ser. Libr. 2008, 55, 62-84. [CrossRef]

37. Densley Tingley, D.; Cooper, S.; Cullen, J. Understanding and overcoming the barriers to structural steel reuse, a UK perspective. J. Clean. Prod. 2017, 148, 642-652. [CrossRef]

38. Sanchez, B.; Haas, C. Capital project planning for a circular economy. Constr. Manag. Econ. 2018, 36, 303-312. [CrossRef]

39. Liu, Z.; Osmani, M.; Demian, P.; Baldwin, A. A BIM-aided construction waste minimisation framework. Autom. Constr. 2015, 59, 1-23. [CrossRef]

40. Won, J.; Cheng, J.C.P.; Lee, G. Quantification of construction waste prevented by BIM-based design validation: Case studies in South Korea. Waste Manag. 2016, 49, 170-180. [CrossRef] [PubMed] 
41. Ajayi, S.O.; Oyedele, L.O.; Bilal, M.; Akinade, O.O.; Alaka, H.A.; Owolabi, H.A.; Kadiri, K.O. Waste effectiveness of the construction industry: Understanding the impediments and requisites for improvements. Resour. Conserv. Recycl. 2015, 102, 101-112. [CrossRef]

42. Ma, L.; Le, Y.; Li, H.; Jin, R.; Piroozfar, P.; Liu, M. Regional comparisons of contemporary construction industry sustainable concepts in the chinese context. Sustainability 2018, 10, 3831. [CrossRef]

43. Soust-Verdaguer, B.; Llatas, C.; García-Martínez, A. Critical review of bim-based LCA method to buildings. Energy Build. 2017, 136, 110-120. [CrossRef]

44. Li, C.Z.; Hong, J.; Xue, F.; Shen, G.Q.; Xu, X.; Mok, M.K. Schedule risks in prefabrication housing production in Hong Kong: A social network analysis. J. Clean. Prod. 2016, 134, 482-494. [CrossRef]

45. ISO 16739-1:2018 Industry Foundation Classes (IFC) for Data Sharing in the Construction and Facility Management Industries_Part 1: Data Schema; International Organization for Standardization: Geneva, Switzerland, 2018; p. 1474.

46. BS 1192-4:2014 Collaborative Production of Information Part 4: Fulfilling Employers Information Exchange Requirements Using COBie-Code of Practice; British Standard Institution: London, UK, 2014; ISBN 978-0-580-85255-8.

47. Menegaki, M.; Damigos, D. A review on current situation and challenges of construction and demolition waste management. Curr. Opin. Green Sustain. Chem. 2018, 13, 8-15. [CrossRef]

48. Oh, M.; Lee, J.; Hong, S.W.; Jeong, Y. Integrated system for BIM-based collaborative design. Autom. Constr. 2015, 58, 196-206. [CrossRef]

49. Ajayi, S.O.; Oyedele, L.O.; Akinade, O.O.; Bilal, M.; Alaka, H.A.; Owolabi, H.A.; Kadiri, K.O. Attributes of design for construction waste minimization: A case study of waste-to-energy project. Renew. Sustain. Energy Rev. 2017, 73, 1333-1341. [CrossRef]

50. PAS 1192-2:2013 Specification for Information Management for the Capital/Delivery Phase of Construction Projects Using Building Information Modelling; British Standard Institution: London, UK, 2013; ISBN 978-0-580-78136-0.

51. Santos, R.; Costa, A.A.; Grilo, A. Bibliometric analysis and review of building information modelling literature published between 2005 and 2015. Autom. Constr. 2017, 80, 118-136. [CrossRef]

52. Kassem, M.; Succar, B. Macro BIM adoption: Comparative market analysis. Autom. Constr. 2017, 81, $286-299$. [CrossRef]

53. Cavka, H.B.; Staub-French, S.; Poirier, E.A. Levels of BIM compliance for model handover. J. Inf. Technol. Constr. 2018, 23, 243-258.

54. Re Cecconi, F.; Maltese, S.; Dejaco, M.C. Leveraging BIM for digital built environment asset management. Innov. Infrastruct. Solut. 2017, 2, 14. [CrossRef]

55. Kivits, R.A.; Furneaux, C. BIM: Enabling sustainability and asset management through knowledge management. Sci. World J. 2013, 2013, 983721. [CrossRef]

56. Alwan, Z.; Jones, P.; Holgate, P. Strategic sustainable development in the UK construction industry, through the framework for strategic sustainable development, using building information modelling. J. Clean. Prod. 2017, 140, 349-358. [CrossRef]

57. Esa, M.R.; Halog, A.; Rigamonti, L. Strategies for minimizing construction and demolition wastes in Malaysia. Resour. Conserv. Recycl. 2017, 120, 219-229. [CrossRef]

58. Chong, H.-Y.; Lee, C.-Y.; Wang, X. A mixed review of the adoption of building information modelling (BIM) for sustainability. J. Clean. Prod. 2017, 142, 4114-4126. [CrossRef]

59. Joblot, L.; Paviot, T.; Deneux, D.; Lamouri, S. Literature review of Building Information Modeling (BIM) intended for the purpose of renovation projects. In Proceedings of the 20th IFAC World Congress, Toulouse, France, 9-14 July 2017; Volume 50, pp. 10518-10525.

60. Zuo, J.; Zhao, Z.-Y. Green building research-current status and future agenda: A review. Renew. Sustain. Energy Rev. 2014, 30, 271-281. [CrossRef]

61. Ness, D.; Swift, J.; Ranasinghe, D.C.; Xing, K.; Soebarto, V. Smart steel: New paradigms for the reuse of steel enabled by digital tracking and modelling. J. Clean. Prod. 2015, 98, 292-303. [CrossRef]

62. Akbarnezhad, A.; Ong, K.C.G.; Chandra, L.R. Economic and environmental assessment of deconstruction strategies using building information modeling. Autom. Constr. 2014, 37, 131-144. [CrossRef]

63. Akanbi, L.A.; Oyedele, L.O.; Akinade, O.O.; Ajayi, A.O.; Davila Delgado, M.; Bilal, M.; Bello, S.A. Salvaging building materials in a circular economy: A BIM-based whole-life performance estimator. Resour. Conserv. Recycl. 2018, 129, 175-186. [CrossRef] 
64. Akinade, O.O.; Oyedele, L.O.; Ajayi, S.O.; Bilal, M.; Alaka, H.A.; Owolabi, H.A.; Bello, S.A.; Jaiyeoba, B.E.; Kadiri, K.O. Design for Deconstruction (DfD): Critical success factors for diverting end-of-life waste from landfills. Waste Manag. 2017, 60, 3-13. [CrossRef] [PubMed]

65. Sanchez, B.; Haas, C. A novel selective disassembly sequence planning method for adaptive reuse of buildings. J. Clean. Prod. 2018, 183, 998-1010. [CrossRef]

66. Bilal, M.; Oyedele, L.O.; Qadir, J.; Munir, K.; Akinade, O.O.; Ajayi, S.O.; Alaka, H.A.; Owolabi, H.A. Analysis of critical features and evaluation of BIM software: Towards a plug-in for construction waste minimization using big data. Int. J. Sustain. Build. Technol. Urban Dev. 2015, 6, 211-228. [CrossRef]

67. Tibaut, A.; Zazula, D. Sustainable management of construction site big visual data. Sustain. Sci. 2018, 13, 1311-1322. [CrossRef]

68. Akinade, O.O.; Oyedele, L.O.; Bilal, M.; Ajayi, S.O.; Owolabi, H.A.; Alaka,H.A.; Bello, S.A. Waste minimisation through deconstruction: A BIM based deconstructability assessment score (BIM-DAS). Resour. Conserv. Recycl. 2015, 105, 167-176. [CrossRef]

69. Volk, R.; Luu, T.H.; Mueller-Roemer, J.S.; Sevilmis, N.; Schultmann, F. Deconstruction project planning of existing buildings based on automated acquisition and reconstruction of building information. Autom. Constr. 2018, 91, 226-245. [CrossRef]

70. Lu, W.; Webster, C.; Chen, K.; Zhang, X.; Chen, X. Computational Building Information Modelling for construction waste management: Moving from rhetoric to reality. Renew. Sustain. Energy Rev. 2017, 68, 587-595. [CrossRef]

71. Hossain, M.U.; Ng, S.T. Critical consideration of buildings' environmental impact assessment towards adoption of circular economy: An analytical review. J. Clean. Prod. 2018, 205, 763-780. [CrossRef]

72. Röck, M.; Hollberg, A.; Habert, G.; Passer, A. LCA and BIM: Visualization of environmental potentials in building construction at early design stages. Build. Environ. 2018, 140, 153-161. [CrossRef]

73. Minunno, R.; O'Grady, T.; Morrison, G.M.; Gruner, R.L.; Colling, M. Strategies for applying the circular economy to prefabricated buildings. Buildings 2018, 8, 125. [CrossRef]

74. Peng, C. Calculation of a building's life cycle carbon emissions based on Ecotect and building information modeling. J. Clean. Prod. 2016, 112, 453-465. [CrossRef]

75. Ajayi, S.; Oyedele, L.; Ceranic, B.; Gallanagh, M.; Kadiri, K. Life cycle environmental performance of material specification: A BIM-enhanced comparative assessment. Int. J. Sustain. Build. Technol. Urban Dev. 2015, 6, 14-24. [CrossRef]

76. Eleftheriadis, S.; Mumovic, D.; Greening, P. Life cycle energy efficiency in building structures: A review of current developments and future outlooks based on BIM capabilities. Renew. Sustain. Energy Rev. 2017, 67, 811-825. [CrossRef]

77. Marzouk, M.; Abdelkader, E.M.; Al-Gahtani, K. Building information modeling-based model for calculating direct and indirect emissions in construction projects. J. Clean. Prod. 2017, 152, 351-363. [CrossRef]

78. Marzouk, M.; El-zayat, M.; Aboushady, A. Assessing environmental impact indicators in road construction projects in developing countries. Sustainability 2017, 9, 843. [CrossRef]

79. Yeheyis, M.; Hewage, K.; Alam, M.S.; Eskicioglu, C.; Sadiq, R. An overview of construction and demolition waste management in Canada: A lifecycle analysis approach to sustainability. Clean Technol. Environ. Policy 2013, 15, 81-91. [CrossRef]

80. de Magalhães, R.F.; Danilevicz, Â.D.M.F.; Saurin, T.A. Reducing construction waste: A study of urban infrastructure projects. Waste Manag. 2017, 67, 265-277. [CrossRef]

81. Cai, G.; Waldmann, D. A material and component bank to facilitate material recycling and component reuse for a sustainable construction: Concept and preliminary study. Clean Technol. Environ. Policy 2019, 21, 2015-2032. [CrossRef]

82. Koutamanis, A.; van Reijn, B.; van Bueren, E. Urban mining and buildings: A review of possibilities and limitations. Resour. Conserv. Recycl. 2018, 138, 32-39. [CrossRef]

83. Norman, A.T. Blockchain Technology Explained: The Ultimate Beginner's Guide About Blockchain Wallet, Mining, Bitcoin, Ethereum, Litecoin, Zcash, Monero, Ripple, Dash, IOTA and Smart Contracts; CreateSpace Independent Publishing Platform: Scotts Valley, CA, USA, 2017; ISBN 978-1-981522-02-6.

84. Turk, Ž.; Klinc, R. Potentials of blockchain technology for construction management. In Proceedings of the Construction Conference 2017, CCC 2017, Primosten, Croat, 19-22 June 2017; Volume 196, pp. 638-645. 
85. Von Haller Grønbæk, M. Blockchain 2.0, Smart Contracts and Challenges. Available online: https:// www.twobirds.com/en/news/articles/2016/uk/blockchain-2-0-smart-contracts-and-challenges (accessed on 15 March 2019).

86. Szabo, N. Formalizing and Securing Relationships on Public Networks. Available online: https:/ojphi.org/ ojs/index.php/fm/article/view/548 (accessed on 15 March 2019).

87. Ma, Z.; Ren, Y. Integrated application of BIM and GIS: An overview. In Proceedings of the Construction Conference 2017, CCC 2017, Primosten, Croat, 19-22 June 2017; Volume 196, pp. 1072-1079.

88. Irizarry, J.; Karan, E.P.; Jalaei, F. Integrating BIM and GIS to improve the visual monitoring of construction supply chain management. Autom. Constr. 2013, 31, 241-254. [CrossRef]

89. Ohori, K.; Biljecki, F.; Kumar, K.; Ledoux, H.; Stoter, J. Modeling cities and landscapes in 3D with CityGML. In Building Information Modeling: Technology Foundations and Industry Practice; Springer: Berlin/Heidelberg, Germany, 2018; pp. 199-215. ISBN 978-3-319-92861-6.

90. Al-Saggaf, A.; Jrade, A. Benefits of integrating BIM And GIS in construction management and control. In Proceedings of the 5th International Construction Specialty Conference of the Canadian Society for Civil Engineering (ICSC), Vancouver, BC, Canada, 7-10 June 2015.

91. Mignard, C.; Nicolle, C. Merging BIM and GIS using ontologies application to urban facility management in ACTIVe3D. Spec. Issue Role Ontol. Future Web-Based Ind. Enterp. 2014, 65, 1276-1290. [CrossRef]

92. Aziz, R.F.; Hafez, S.M. Applying lean thinking in construction and performance improvement. Alex. Eng. J. 2013, 52, 679-695. [CrossRef]

93. Nascimento, D.; Caiado, R.; Tortorella, G.; Ivson, P.; Meirino, M. Digital obeya room: Exploring the synergies between BIM and lean for visual construction management. Innov. Infrastruct. Solut. 2018, 3, 19. [CrossRef]

94. Mazlum, S.K.; Pekeriçli, M.K. Lean design management-An evaluation of waste items for architectural design process. METU J. Fac. Archit. 2016, 33, 1-20. [CrossRef]

95. Liker, J.K. The Toyota Way: 14 Management Principles from the World's Greatest Manufacturer; Safari Books Online; McGraw-Hill: New York, NY, USA, 2004; ISBN 0-07-139231-9.

96. Ohno, T. Toyota Production System: Beyond Large-Scale Production; Productivity Press: Cambridge, UK, 1988; ISBN 0-915299-14-3.

97. Giovanny Sanchez-Rivera, O.; Alberto Galvis-Guerra, J.; Porras-Diaz, H.; Damian Ardila-Chacon, Y.; Augusto Martinez-Martinez, C. BrIM 5D models and lean construction for planning work activities in reinforced concrete bridges. Rev. Fac. Ing. Univ. Pedagog. Tecnol. Colomb. 2017, 26, 39-50.

98. Sacks, R.; Radosavljevic, M.; Barak, R. Requirements for building information modeling based lean production management systems for construction. Autom. Constr. 2010, 19, 641-655. [CrossRef]

99. Ma, Z.; Zhang, D.; Li, J. A dedicated collaboration platform for integrated project delivery. Autom. Constr. 2018, 86, 199-209. [CrossRef]

100. Li, X.; Li, Z.; Wu, G. Modular and offsite construction of piping: Current barriers and route. Appl. Sci. 2017, 7, 547. [CrossRef]

101. Abanda, F.H.; Tah, J.H.M.; Cheung, F.K.T. BIM in off-site manufacturing for buildings. J. Build. Eng. 2017, 14, 89-102. [CrossRef]

102. Volk, R.; Stengel, J.; Schultmann, F. Building information modeling (BIM) for existing buildings-Literature review and future needs. Autom. Constr. 2014, 38, 109-127. [CrossRef]

103. Akinade, O.O.; Oyedele, L.O.; Omoteso, K.; Ajayi, S.O.; Bilal, M.; Owolabi, H.A.; Alaka, H.A.; Ayris, L.; Henry Looney, J. BIM-based deconstruction tool: Towards essential functionalities. Int. J. Sustain. Built Environ. 2017, 6, 260-271. [CrossRef]

104. Liu, H.; Singh, G.; Lu, M.; Bouferguene, A.; Al-Hussein, M. BIM-based automated design and planning for boarding of light-frame residential buildings. Autom. Constr. 2018, 89, 235-249. [CrossRef]

105. Webinar: 2016 Level of Development Specification Update; BIMForum: Alexandria, VA, USA, 25 August 2016.

106. Cuccurullo, C.; Aria, M.; Sarto, F. Foundations and trends in performance management. A twenty-five years bibliometric analysis in business and public administration domains. Scientometrics 2016, 108, 595-611. [CrossRef]

(C) 2020 by the authors. Licensee MDPI, Basel, Switzerland. This article is an open access article distributed under the terms and conditions of the Creative Commons Attribution (CC BY) license (http://creativecommons.org/licenses/by/4.0/). 